\title{
Development of the Retinofugal Projections in the Embryonic and Larval Zebrafish (Brachydanio rerio)
}

\author{
JOHN D. BURRILL AND STEPHEN S. EASTER, JR. \\ Neuroscience Program (J.D.B., S.S.E.) and Department of Biology (S.S.E.), \\ University of Michigan, Ann Arbor, Michigan 48109-1048
}

\begin{abstract}
Studies of the projection from the vertebrate retina have contributed significantly to current concepts of neural development. The zebrafish has recently become a favored system for the study of development in general and neural development in particular. Although the development of both the optic nerve and the retinotectal projection of the zebrafish has been described, the retinofugal projection in its entirety has not. This paper describes it and also addresses the issue of projectional exuberance: i.e., transient projections to targets that are not innervated in the adult.

The retinofugal projection of embryonic and larval zebrafish (32 hours to 7 days post-fertilization) was labeled by intraocular injection of $\mathrm{DiI}\left(1,1^{\prime}\right.$-dioctadecyl-3,3,3',3', tetramethylindocarbocyanine perchlorate) and then studied in wholemounts and sections.

The first optic axons crossed the chiasm at 32 hours post-fertilization and projected in a straight line to reach the tectum at about 44 hours. At 48 hours, a few optic axons deviated along either the tract of the posterior commissure or the tract of the postoptic commissure. By 72 hours (about the time of hatching) optic axons arborized in ten distinct regions, termed arborization fields. At 6-7 days post-fertilization, the same ten arborization fields (nine contralateral, one bilateral) were evident. Most of the arborization fields were located in the superficial neuropil and were not associated with morphologically identifiable clusters of somata. On the basis of various landmarks, the ten arborization fields are identified as precursors of retinorecipient nuclei previously described in other adult cypriniform fishes.

The development was characterized by the nearly complete absence of any transient projections. Thus, the idea that axonal outgrowth is initially exuberant and trimmed back later is not supported by these results. 1994 Wiley-Liss, Inc.
\end{abstract}

Key words: retinal projections, retinal efferents, teleost, transient projections, visual pathways

The issue of how growing axons reach their targets is central to developmental neurobiology. Over the last 20 years, the idea that projections within the central nervous system (CNS) form with an initial "exuberant" phase, characterized by abundant terminals in incorrect locations, followed by a second phase, removal of the incorrect terminals, has gained considerable credence. The term exuberance has been used to describe two types of misplaced terminals: those in the wrong place of a particular target field (e.g., the optic tectum) and those in a target field that is not innervated in the adult. In this paper, we deal only with the second meaning. The most striking examples have come from the retinofugal projections of rodents. Land and Lund (1979) showed that the uncrossed retinocollicular projection was much more substantial early in development than later, and Bunt and Lund (1981) and Müller and Holländer (1988) described transient retino- retinal projections. Others have shown that retinal axons in neonatal hamsters and rats form terminals in a variety of incorrect targets, including non-visual areas of the thalamus, the hypothalamus, midbrain, and hindbrain (Kato, 1983; Frost, 1984; Cooper and Cowey, 1990a,b; Langdon and Frost, 1991; Simon and O'Leary, 1992). These terminals can be experimentally stabilized and mediate function (Frost, 1981; Frost and Métin, 1985; Kato et al., 1985b; Campbell and Frost, 1988).

We wondered if similar events occurred in the zebrafish. An earlier study (Stuermer, 1988) emphasized the orderliness of the initial retinotectal projection in zebrafish, but did not mention other, non-tectal, targets. Perhaps misdi-

\footnotetext{
Accepted February 15, 1994.

Address reprint requests to Dr. John D. Burrill at his present address, Molecular Neurobiology Laboratory, Salk Institute, La Jolla, CA 92037.
} 
rected growth and subsequent removal occurred later than the period studied by Stuermer, or perhaps they did not occur at all. An additional reason for wanting to know more about the zebrafish derives from the fact that the retinotectal projection in fish and amphibia has played such a central role in the formulation of current beliefs about neural specificity (Easter et al., 1985), and the absence of information about the accuracy of initial targeting impedes the construction of plausible hypotheses to explain the formation of specific connections. Accordingly, we undertook this study of the development of all the retinofugal projections in zebrafish.

The main visual processing center in the anamniotic vertebrates is the midbrain optic tectum, but the retina also projects to the hypothalamus, the thalamus, and the pretectal region (Braford and Northcutt, 1983; Beazley, 1984; Northcutt and Wullimann, 1987). Studies of the development of the visual system of anamniotes have concentrated on the retinotectal projection (reviewed in Schmidt, 1982; Beazley, 1984); other retinofugal projections were examined in only a few studies (Pinganaud, 1980, 1987; Rettig et al., 1981; Rettig, 1988).

The cypriniform teleost, Brachydanio rerio, or zebrafish, offers several advantages for the examination of the development of all the retinofugal projections. First, the early development of the retinotectal projection has been well studied; the first retinal ganglion cells differentiate around 28 hours post-fertilization (Nawrocki, 1985), extend an axon between 32 and 34 hours, reach the optic tectum around 44 hours, and terminate shortly thereafter (Stuermer, 1988; Burrill et al., 1989; Stuermer et al., 1990), prior to hatching, which occurs around 72 hours. Second, during the development of the visual system the zebrafish brain is relatively simple, consisting of a bilateral scaffold of three commissures and five tracts at 24 hours, which expands to five commissures and seven tracts at 48 hours (Wilson et al., 1990; Chitnis and Kuwada, 1990). This allows the examination of retinofugal projections on a relatively well-defined background. Finally, the embryos are sufficiently small and transparent that they can be viewed as wholemounts, thus providing a three-dimensional accurate view of the labeled projection.

In this paper, we provide an anatomical description of the development of the retinofugal projection, including the optic tract and ten arborization fields. It is very orderly, with no sign of exuberant projections that must be removed later.

\section{Abbreviations}

$\begin{array}{ll}\text { nAOD } & \text { n. accessorius opticus dorsalis } \\ \text { nAOV } & \text { n. accessorius opticus ventralis } \\ \text { nA } & \text { n. anterioris thalami } \\ \text { nI } & \text { n. intermedius thalami } \\ \text { nPPp } & \text { n. preopticus parvicellularis posterioris } \\ \text { nPC } & \text { n. pretectalis centralis } \\ \text { nPPd } & \text { n. pretectalis periventricularis pars dorsalis } \\ \text { nPPv } & \text { n. pretectalis periventricularis pars ventralis } \\ \text { nPSp } & \text { n. pretectalis superficialis pars parvicellularis } \\ \text { nSC } & \text { n. suprachiasmaticus } \\ \text { nVL } & \text { n. ventrolateralis thalami } \\ \text { TO } & \text { tectum opticum } \\ \text { TPC } & \text { tract of the posterior commissure } \\ \text { TPOC } & \text { tract of the postoptic commissure }\end{array}$

\section{MATERIALS AND METHODS General}

Zebrafish embryos were obtained from our own breeding colony and raised as previously described (Wilson et al., 1990 ) except that some were raised in $0.2 \mathrm{mM}$ phenylthiocarbamide (1-phenyl-2-thiourea, Sigma) to block the development of pigmentation (Westerfield, 1989). Phenylthiocarbamide did not affect the development of the embryos or the eye (SSE, unpublished observations). Embryos were collected as blastulas approximately 1 hour after fertilization and staged according to the number of blastomeres. The time of fertilization was estimated to an accuracy of 15 minutes (Westerfield, 1989). Ages are given as hours or days post-fertilization.

\section{Labeling of the optic axons and retinal ganglion cells}

Embryos and larvae (32 hours to 7 days of age) were killed by over-anesthetizing them in MS-222 (3-aminobenzoic acid ethyl ester), fixed overnight in $4 \%$ phosphatebuffered formalin ( $\mathrm{pH} 7.4$ ), and then labeled intraocularly with DiI (1,1'-dioctadecyl-3,3,3',3',tetramethylindocarbocyanine perchlorate; Honig and Hume, 1986; Godement et al., 1987). The DiI was dissolved in N,N-dimethylformamide $(2.5 \mathrm{mg} / \mathrm{ml})$ and either pressure injected as a solution, or recrystalized and applied as crystals. The DiI was allowed to transport overnight at $4^{\circ} \mathrm{C}$. The fluorescence was photoconverted to a permanent, electron-dense reaction product by photoexcitation of the dye in the presence of $0.08 \%$ diaminobenzidene (DAB; $20 \mathrm{mg} / 25 \mathrm{ml}$; McConnell et al., 1989). The embryos were then cleared in glycerin, wholemounted between two coverslips, and viewed with differential interference contrast optics (DIC). This range of ages was chosen because at 32 hours the first axons emerge from the eye, and by $6-7$ days the larvae are feeding freely and seem to have a functional visual system. Moreover, the brain is approximately the same size over this period, and therefore readily compared across ages.

\section{Methacrylate sections}

Embryos were fixed overnight in $4 \%$ phosphate-buffered formalin, labeled with DiI and photoconverted, post-fixed for 2-3 hours in $4 \%$ glutaraldehyde in $0.1 \mathrm{M}$ phosphate buffer, dehydrated in alcohol, and embedded in glycol methacrylate (Polaron). Transverse serial sections (10 $\mu \mathrm{m})$ were cut and stained with $1.25 \%$ methylene blue.

\section{RESULTS \\ The identification of the arborization fields}

Axonal arborizations were easily recognized in both wholemounts and sections; the axons were thin, beaded, and branched, with the branches oriented randomly (Figs. 1,11). The cluster of branches delimited the arborization field (AF), as shown by the dashed line in Figure 1.

\section{The endpoint: Ten AFs and one retinopetal projection at 6-7 days}

Ten retinofugal AFs were identified in 6-7 day larvae and numbered AF-1 to AF-10, in a ventrodorsal progression (Fig. 2). Eight of them lay wholly or partly lateral to the optic tract, and, therefore, were evident in wholemounts. Two others, AF-5 and AF-8, were obscured by the optic 


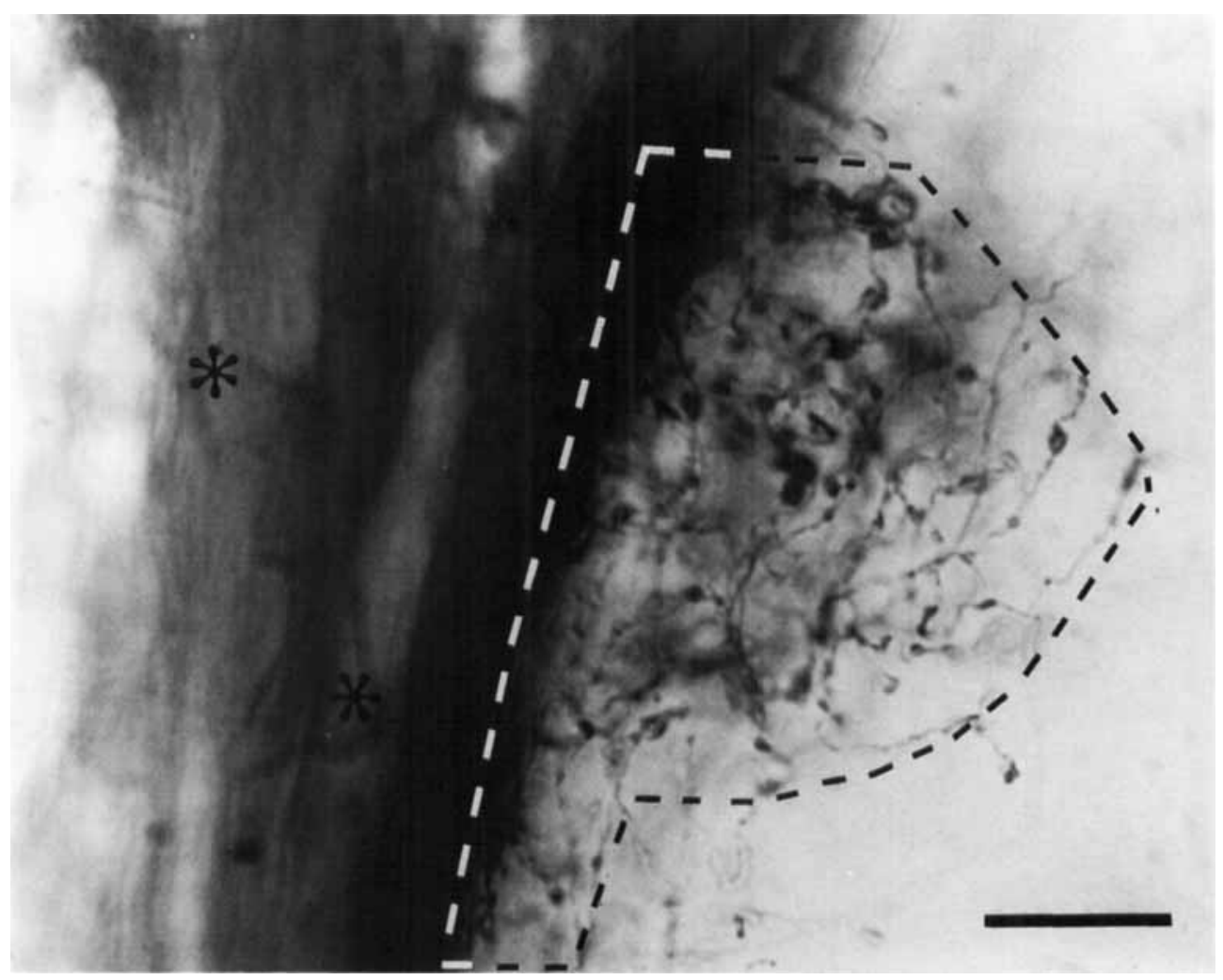

Fig. 1. An arborization field (AF) from a 6-7 day zebrafish wholemount. (Lateral view: rostral, left; dorsal, up.) A loose collection of randomly oriented beaded optic axons meander throughout a $900 \mu \mathrm{m}^{2}$ region (dashed outline) adjacent to the parallel fascicles of optic axons (asterisks) and form AF-2. A lower magnification view of AF-2 is shown in Figure 10B. Scale bar $=10 \mu \mathrm{m}$. tract, and could be discerned only in sections (Figs. 2, 9). In the Discussion, all ten AFs will be assigned to retinorecipient targets that have been previously described in adult cypriniformes (see Table 2). At this point we note that AF-10 is the presumptive optic tectum.

All ten AFs were contralateral, but one of them also had an ipsilateral component. The only ipsilateral arborizations were in the hypothalamus, contiguous with contralateral AF-1 (see Figs. 6, 8, 9, 11); we call this ipsilateral AF-1. Of the 196 embryos examined, only two had labeled ipsilateral optic axons anywhere other than AF-1, and both of these had only a single unarborized axon (Figs. 8D, 11A). No labeled optic axons were ever observed in the contralateral optic nerve in either wholemounts or sections. We conclude that ipsilateral projection errors are extremely rare, and a transient retinoretinal projection is non-existent.

Intraocular injections made prior to 5.5 days labeled no somata in the brain. After this age, retrogradely labeled somata were found in the rostral telencephalon. They constitute the nucleus olfactoretinalis (Northcutt and Willimann, 1987; von Bartheld and Meyer, 1988), which appears in the zebrafish at about 5 days (A. Rusoff and L. Ross, personal communication). The axons from this nucleus projected caudally and joined the main optic tract in the ventral diencephalon approximately $30 \mu \mathrm{m}$ dorsal to AF-1 (Fig. 2B).

$\boldsymbol{A F}$-I. This was located immediately dorsal to the optic chiasm and extended caudally into the hypothalamus (Figs. $7-9,10 \mathrm{~A}, 11 \mathrm{~A}$ ), with a diffuse dorsocaudal extension. In transverse sections, AF-I was located bilaterally on the medial edge of the ventral neuropil, with a few terminals extending among the cell nuclei (Figs. 8A,E, 9C-E). The amount of arbor on both sides of the midline was equal in most of the embryos examined.

The ipsilateral arborizations in AF-1 did not result from an incomplete decussation at the chiasm, since no labeled axons either coursed in the ipsilateral optic tract or projected dorsally from the optic chiasm. Instead, they initially crossed the midline in the optic chiasm and then redecussated dorsal to the optic chiasm to terminate ipsilaterally (Figs. 8D,E, 9B,C)

$\boldsymbol{A F}$-2. This was a relatively sparse AF located approximately $50 \mu \mathrm{m}$ dorsal of the optic chiasm in the caudal portion of the main optic tract (Figs. 1, 7, 10B). The transverse sections showed that AF-2 was located superficially in the lateral neuropil with portions of it embedded in the main optic tract (Figs. 8, 9).

$\boldsymbol{A F}$-3. This was located approximately $50 \mu \mathrm{m}$ caudal to the main optic tract, about $10 \mu \mathrm{m}$ dorsal to AF-2 (Fig. 2). The axons that innervated AF-3 projected caudally from the main optic tract either through or just dorsal to AF-2. Transverse sections showed that the terminals of AF-3 lay in the medial part of the lateral neuropil, adjacent to and occasionally contacting the central collection of cell nuclei (Figs. 8E,F, 9E,F), medial to both the main optic tract and to $\mathrm{AF}-2$.

$\boldsymbol{A F}-4$. Beginning at approximately the level of AF-2 and extending $60 \mu \mathrm{m}$ dorsally in the rostral portion of the main optic tract was the cigar-shaped AF-4 (Figs. 7, 10D). Most of it was located within the main optic tract, but occasionally 


\section{A}

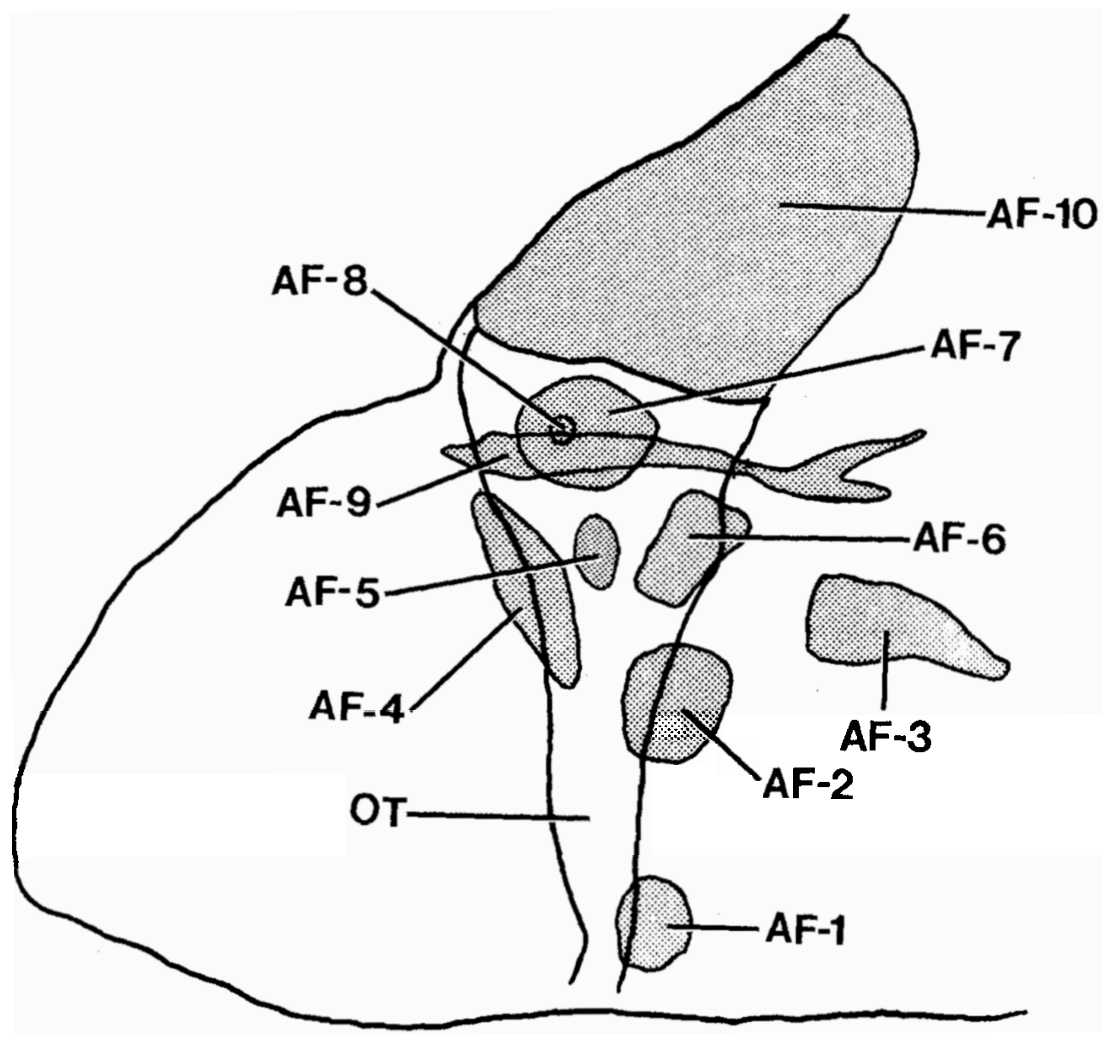

B

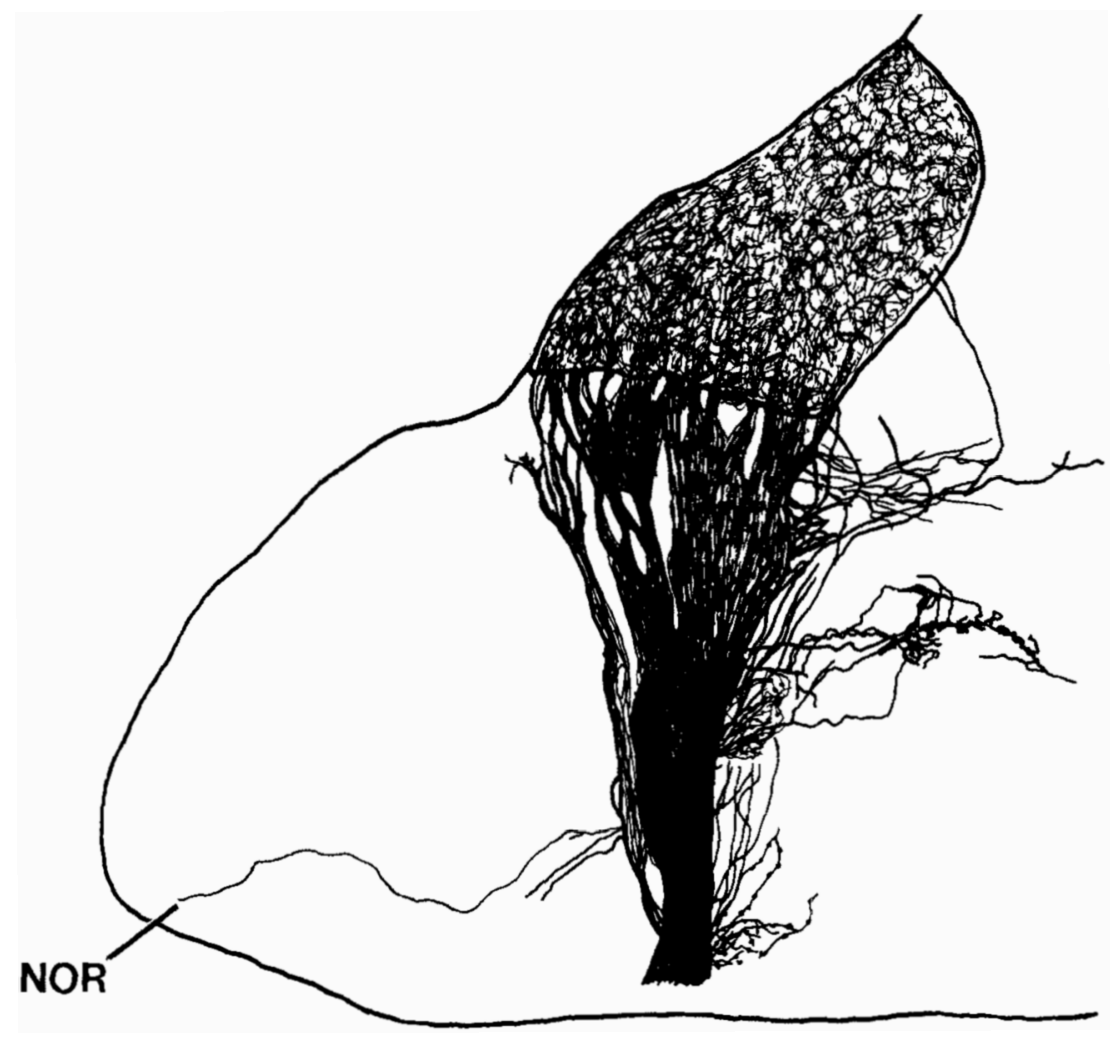

Fig. 2. The retinofugal AFs present at 6-7 days. (Wholemounts, lateral views: rostral, left; dorsal, up.) A: Schematic diagram of the retinofugal AFs (stippled) present at 6-7 days. The approximate locations of AF-5 and AF-8 are also shown, but they are not visible in the wholemounts. B: Camera lucida drawing of the labeled optic axons and their arborizations. The cell bodies of the retinopetal projection in $B$ were removed during the dissection of the larvae. NOR, nucleus olfactoretinalis; $\mathrm{OT}^{\top}$, optic tract. Scale bar $=50 \mu \mathrm{m}$. 
its dorsal tip extended rostral to the tract. In transverse sections, AF-4 was located superficially within the main optic tract and the surrounding neuropil (Figs. 8C, 9A-C).

$A F-5$. A branch of optic axons that left the main optic tract approximately $75 \mu \mathrm{m}$ ventral of AF-4 and traversed the middle of the lateral neuropil was evident only in the transverse sections. At approximately the level of AF-4 in the middle of the lateral neuropil optic axons within this medial branch arborized in AF-5 (Figs. 8, 9, 11B). A number of the optic axons projected dorsally from AF-5 toward AF-9 and $A F-10$, but it was not possible to follow individual axons to determine if they arborized within two AFs.

$\boldsymbol{A F}$-6. This was located in the caudal half of the optic tract at approximately the level of the dorsal portion of AF-4, $35 \mu \mathrm{m}$ dorsal to AF-2 (Figs. 7, 10B). Axons projected up to $50 \mu \mathrm{m}$ caudal to the main optic tract and arborized in this region. In sections, the axons and terminals of AF-6 were located superficially in the lateral neuropil, often with a number of the terminals embedded within the main optic tract (Fig. 9F).

$\boldsymbol{A F}$-7. AF-7 is a large circular AF in the middle of the main optic tract, about $10 \mu \mathrm{m}$ from the caudal edge of AF-4, the rostral edge of AF-6, and the ventral edge of AF-10 (Figs. 7, 10). Some of the optic axons that entered AF-7 reformed a tight fascicle on the dorsal edge of AF-7 and projected toward AF-10, but it was not possible to determine if they arborized in more than one AF (Fig. 11).

$\boldsymbol{A F}-8$. This was located among a thin strip of cell nuclei within a branch of the optic tract that traveled medial to $\mathrm{AF}-7$ en route to $\mathrm{AF}-10$ (Figs. 9, 11). Because AF-8 was located within a branch of the optic tract it was not possible to identify individual optic axons that arborized in AF-8 and determine if they also projected toward AF-10, or if some optic axons simply projected through AF-8 without arborizing.

AF -9. The rostral portion of AF-9 was approximately 5 $\mu \mathrm{m}$ dorsal to the tip of AF-4 in the region of the TPC and about $5 \mu \mathrm{m}$ rostral to the main optic tract (Figs. 7, 10F). AF-9 extended rostrocaudally across the width of the main optic tract, with the caudal extreme often $50 \mu \mathrm{m}$ beyond the caudal edge of the tract. AF-9 was medial to both AF-7 and $\mathrm{AF}-8$, and in the transverse sections was located near the mouth of the posterior commissure (Figs. 8, 9, 11). Some of the optic axons from AF-9 coalesced on the dorsal side to form an axonal tract that projected toward the deep layers of AF-10 (Figs. 8, 9, 10F, 11).

$A F-10$. Transverse sections revealed that optic axons within AF-10 arborized in both the superficial and deep layers. The majority of optic axons entered AF-10 superfcially, and descended to its deep layers, but some entered the deep layers directly from the ventral aspect (Figs. 8, 9).

\section{The time course of development}

32-44 hours. The initial optic axons exited the eye at 32 hours and projected toward the midline which they crossed in the optic chiasm between 34 and 36 hours. After crossing the midline all of the optic axons traversed the lateral diencephalon in a relatively straight course toward AF-10. None of the labeled optic axons in the embryos less than 44 hours old $(n=38)$ deviated from this straight course to AF-10, suggesting that AF-10 was their initial target.

48 hours. In all of the 48 hour embryos $(n=109)$ the majority of optic axons projected in a straight line toward AF-10, where some of them arborized (Fig. 3). In $37(34 \%)$ of the 48 hour embryos, some of the labeled optic axons deviated from the straight course toward $\mathrm{AF}-10$ along one or both of two pre-existing tracts that could be visualized by DIC optics. In 31 embryos (28\%), a small group (1-10 axons) projected rostrodorsally to run along side the TPC and in nine embryos (8\%), including three with the deviation along the TPC, a single growth cone projected along the tract of the postoptic commissure (TPOC). Tracing the optic axons that deviated along the pre-existing tracts revealed that they were probably the main axon, not collaterals. In the wholemount shown in Figure 3B, the optic axons that deviated along the TPC could be traced 30-50 $\mu \mathrm{m}$ ventral to the TPC, and over this distance none had branches. The final destinations of the growth cones that deviated are unknown, but the growth cones in the ventral deviation may lead to AF-2 and AF-3, and those in the dorsal deviation may project to AF-9. A second possible explanation for the deviations by the optic growth cones is that they are errors, and will either reorient toward AF-10 or be eliminated later in development. Examination of older embryos provides evidence in favor of both of these interpretations (see below).

52-54 hours. The majority of the optic axons in 52-54 hour wholemounts $(n=20)$ projected toward AF-10 in a straight line, and the arborizations were denser than at 48 hours, but still restricted to the same area. Seventeen (85\%) of these embryos also had a small group of optic axons directed along the TPC to form AF-9 (Fig. 4), which supports the interpretation that the axons that deviated at 48 hours were the beginnings of new AFs, and not errors.

In the mid-diencephalon of a few of the 52-54 hour wholemounts $(n=4)$ a single optic axon projected caudally from the main optic tract. In two embryos, it turned dorsally toward AF-10 approximately $25 \mu \mathrm{m}$ caudal to the optic tract (Fig. 4B), suggesting that some of the caudally projecting axons in the 48 hour embryos do reorient toward AF-10. In the other two embryos the growth cones were still oriented caudally, possibly navigating to AF-2 or AF-3.

60 hours. The optic axons arborized in five AFs; however, only four were visible in wholemounts $(n=13)$ (Fig. 5). The projection to AF-9 was denser, and AF-10 was enlarged, extending further caudally than at 52-54 hours. AF-7 was now evident. In some of the 60 hour embryos a small number of optic axons projected bilaterally to AF-1.

Transverse sections through 60 hour embryos $(n=2)$ revealed that the brain was a central collection of cell nuclei surrounded by a superficial neuropil (Fig. 6). Very few cell nuclei were present within the neuropil, and the morphologically distinct clusters of cell nuclei characteristic of the adult brain were not yet identifiable. All four of the AFs visible in the wholemounts, AF-1, AF-7, AF-9, and AF-10, were recognized in the sections (Fig. 6). In addition, AF-5, which was not visible in the wholemounts, could also be discerned. AF-5 was in the mid-diencephalon, medial to the main optic tract. A number of optic axons that entered AF-5 continued dorsally to AF-9, located in the mouth of the posterior commissure. It was not possible to determine if these axons arborized in both AF-5 and AF-9.

66 hours. In 66 hour embryos $(n=7)$, the optic axons arborized in nine different AFs (Fig. 7A,B). AF-1, AF-5, $A F-7$, and AF-9 were more heavily innervated than at 60 hours. AF-10 was also more heavily innervated, and extended farther caudal than at 60 hours. Optic axons now arborized in AF-2, extending 5-10 $\mu \mathrm{m}$ caudal of the main optic tract, and in AF-4 in the rostral portion of the main optic tract. In addition, two to three axons projected 

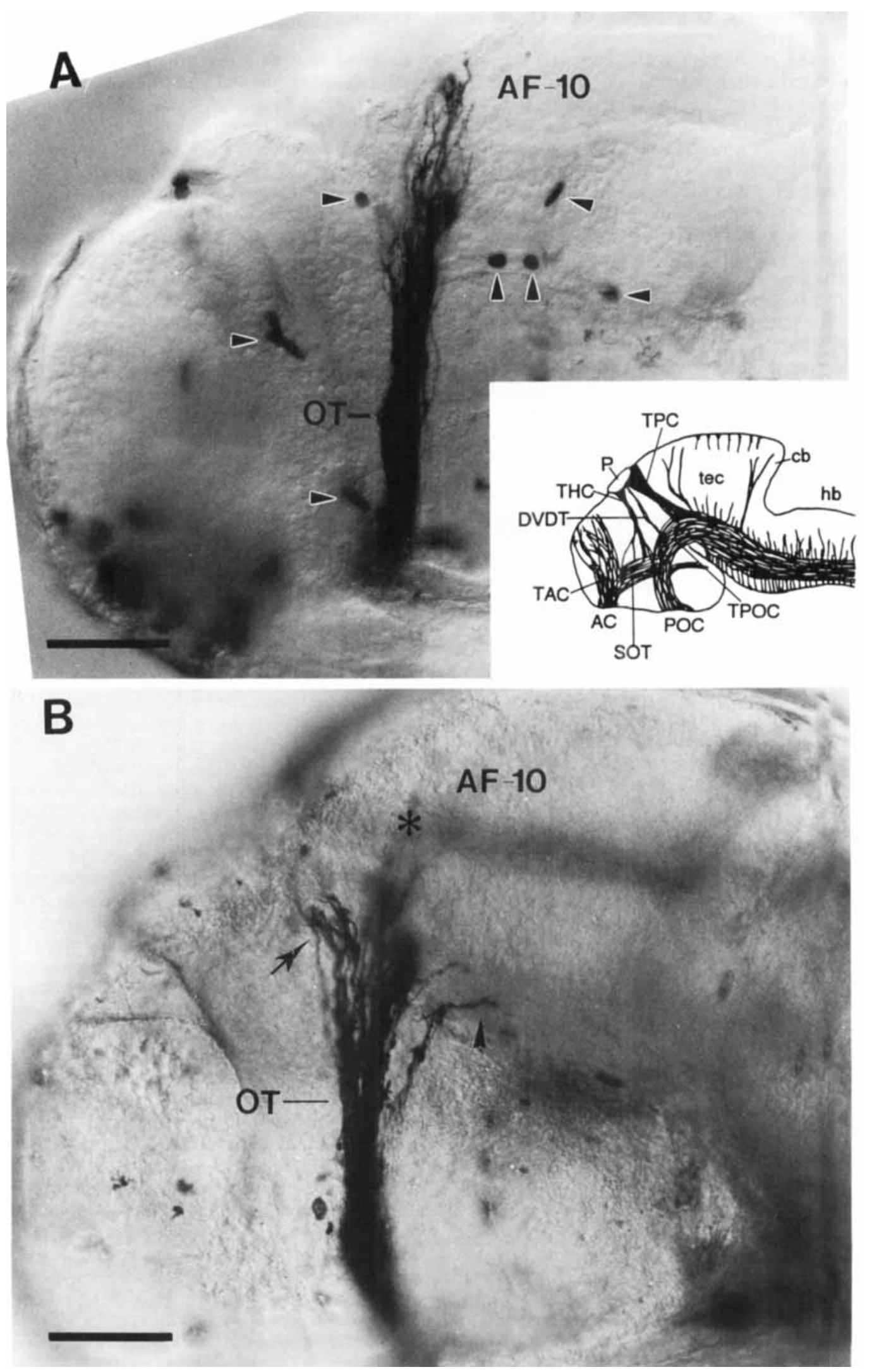

Fig. 3. The optic projection at 48 hours. (Wholemounts, lateral views: rostral, left; dorsal, up.) A: The optic tract (OT) projects toward $\mathrm{AF}-10$ in a relatively straight line with no apparent deviations. The arrowheads indicate blood cells. B: Some of the optic axons $\left(^{*}\right)$ course toward AF-10 in a straight line, but others deviate in the region of two pre-existing tracts (see inset), the TPC (arrow) and the TPOC (arrowhead). Inset: A schematic diagram of the axonal tracts and commis- sures present in a 48 hour wholemount (kindly provided by R. Marcus) $\mathrm{AC}$, anterior commissure; $\mathrm{cb}$, cerebellum; DVDT, dorsoventral diencephalic tract; hb, hindbrain; $\mathrm{P}$, pineal; POC, postoptic commissure; SOT supraoptic tract; TAC, tract of the anterior commissure; tec, tectum; THC, tract of the habenular commissure; TPC, tract of the posterior commissure; TPOC, tract of the postoptic commissure. Scale bars = $50 \mu \mathrm{m}$. 

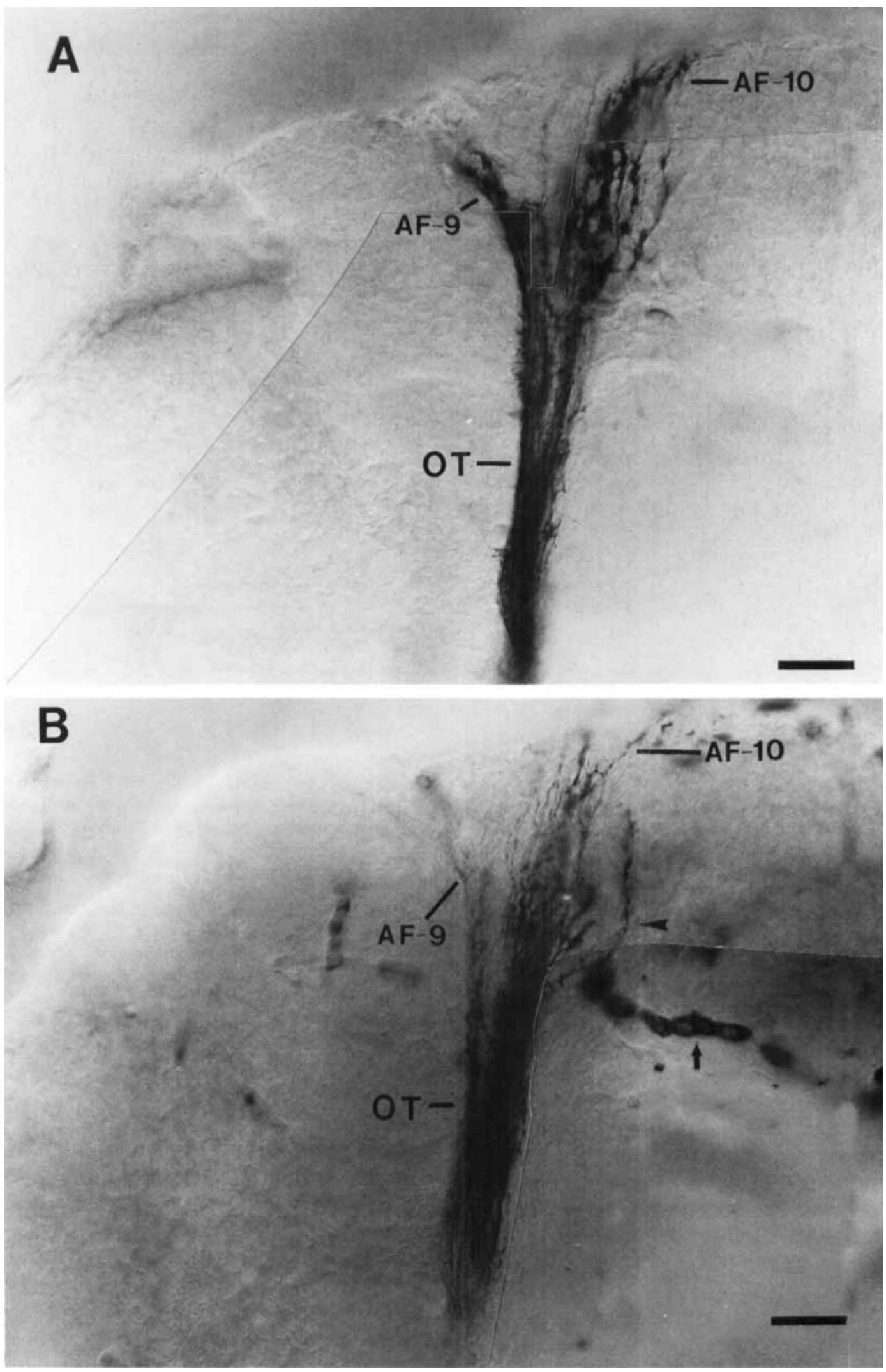

Fig. 4. The optic projection at 52 hours. (Wholemounts, lateral views: rostral, left; dorsal, up). A: The majority of the optic axons project toward AF-10, but a group of optic axons deviates from the main optic tract in the region of the TPC and begins to establish AF-9. Optic axons beginning to innervate AF- 7 are present in the optic tract (OT).
B: An optic axon (arrowhead) projects caudally from the optic tract about $25 \mu \mathrm{m}$ before turning dorsally toward AF-10. A small group of axons also projects toward AF-9 in B, but they are out of focus. The small arrow indicates a string of blood cells. Scale bars $=25 \mu \mathrm{m}$. 


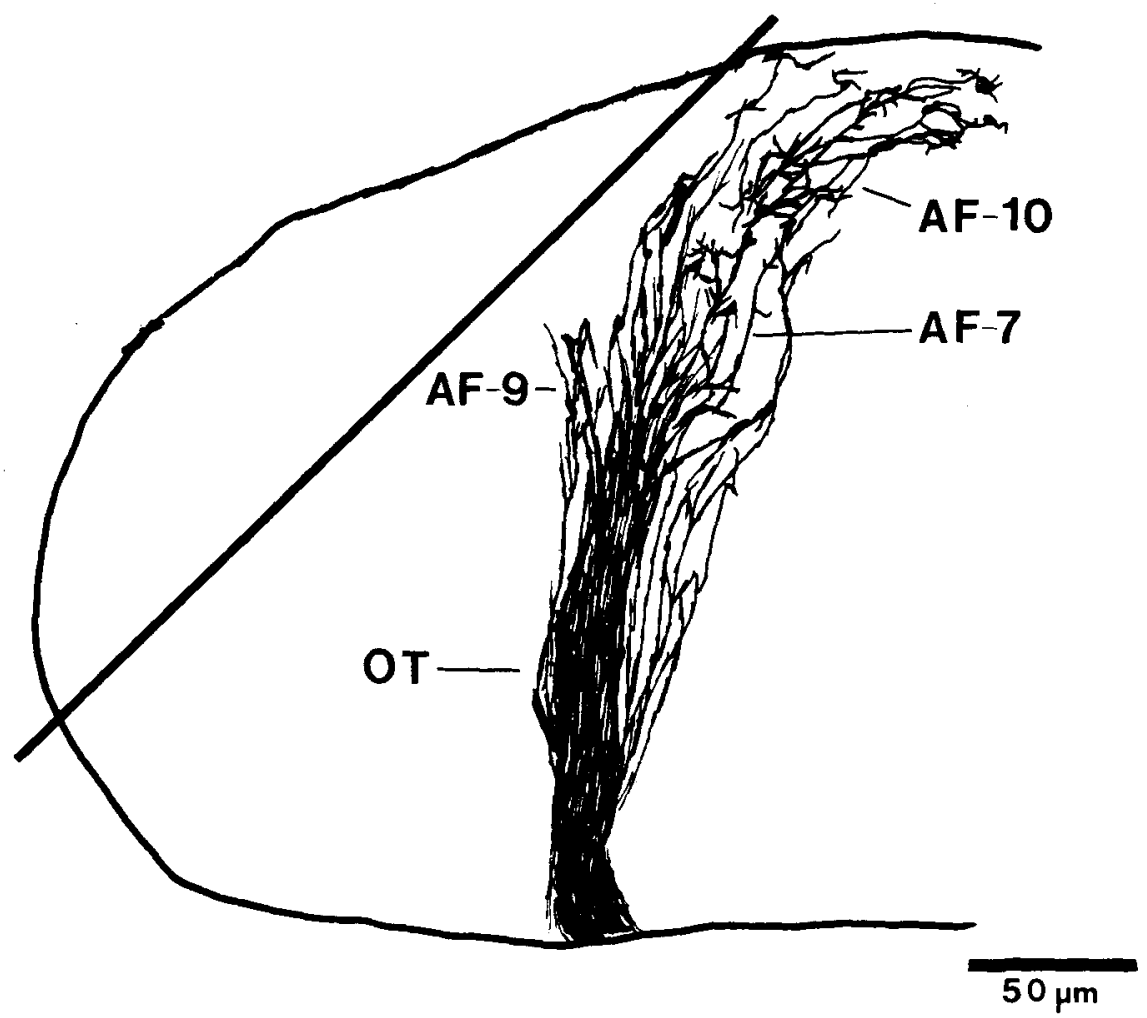

Fig. 5. The optic projection at 60 hours. (Wholemount, lateral view: rostral, left; dorsal, up.) A camera lucida drawing of $A F-7, A F-9$, and $A F-10$. AF- 1 was not present in this embryo, but was present in others of this age (see Fig. 6). The solid line shows the plane of section for Figure 6.

caudally from the main optic tract to form AF-3. In sections $(\mathrm{n}=2)$, all of the AFs were identifiable except AF-6 (Fig. 8).

72 hours and 6-7 days. In 72 hour $(\mathrm{n}=8)$ wholemounts, the same eight AFs (AF-1, AF-2, AF-3, AF-4, AF-6, $\mathrm{AF}-7, \mathrm{AF}-9$, and $\mathrm{AF}-10$ ) visible in 6-7 day wholemounts were visible (Figs. 7,10 ), but the AFs were not as heavily innervated as at 6-7 days. The size and the innervation pattern of AF-10 was now nearly identical with that seen in the 6-7 day larvae. Transverse sections through 72 hour $(n=2)$ embryos and 6-7 day larvae $(n=4)$ were also examined (Figs. 9, 11). In the sections at 72 hours AF-8 was visible for the first time, indicating that all ten $A F$ s were present by 72 hours. The time course of the appearance of the AFs is summarized in Table 1.

In summary, by 66 hours the retina projected to nine of the ten retinofugal AFs that were present in the 6-7 day larvae, and by 72 hours all ten were innervated (Table 1 ). The number of optic axons that terminated in the various fields continued to increase between 66 hours and 6-7 days, but the overall pattern of innervation remained constant. Most of the arborizations were in the (non-cellular) neuropil, and even by 6-7 days the distinctive collections of somata that will characterize most of the retinal targets in the adult brain are not evident.

\section{DISCUSSION}

We have followed the development of the retinofugal projection from the time the first optic axons leave the retina until the larvae become free-feeding. Now we discuss the issue of exuberance, assign adult structures to the AFs (Table 2), and comment on axonal pathfinding mechanisms that may be important for their innervation.

\section{Exuberance}

The optic axons never projected to regions other than the ten AFs that are found at 7 days. There were no transient ipsilateral or contralateral projections, and there was no transient retino-retinal projection. In contrast, during retinofugal development in chick (O'Leary et al., 1983) and rat (Land and Lund, 1979) there is a substantial uncrossed retinal projection that is withdrawn later in development; in rat (Bunt and Lund, 1981) and rabbit (Müller and Holländer, 1988) there is a transient retino-retinal projection; and in hamster and rat there are transient projections to the inferior colliculus, non-visual areas of the thalamus, midbrain, and hindbrain (Kato, 1983; Frost, 1984; Kato et al., 1985b; Cooper and Cowey, 1990a,b; Langdon and Frost, 1991; Simon and O'Leary, 1992). These transient projections are withdrawn prior to hatching in the chick (O'Leary et al., 1983), and prior to the opening of the eyes in rat (Lund and Lund, 1971) and hamster (So et al., 1978). Transient projections to targets not innervated in the adult are not restricted to the visual system, but are also seen in the corticospinal tract (Stanfield et al., 1982; Adams et al., 1983; Kato et al., 1985a), cortico-cortical projections (Dehay et al., 1984; Innocenti and Clarke, 1984; Webster et al., 1991), the fornix (Stanfield et al., 1987), and the olfactory projection (Santacana et al., 1992). In addition, transient cerebro-cerebellar and cerebro-spinal connections have also 


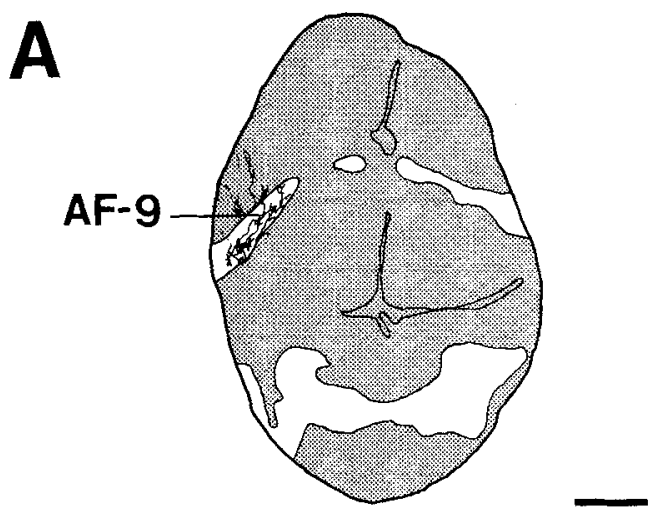

B

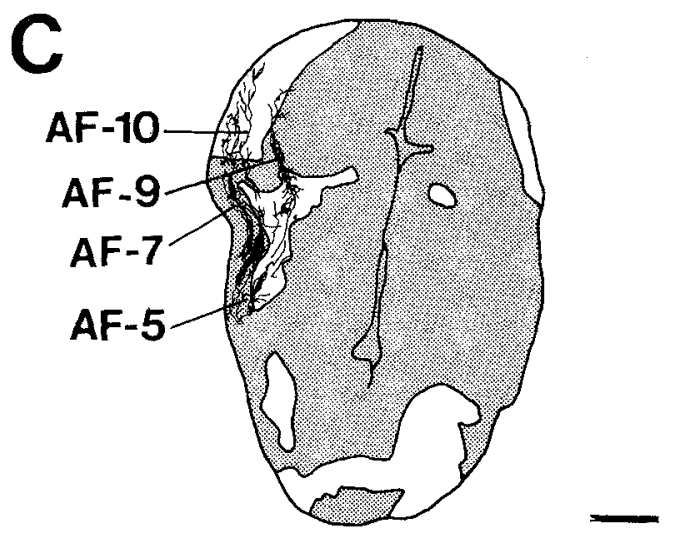

D
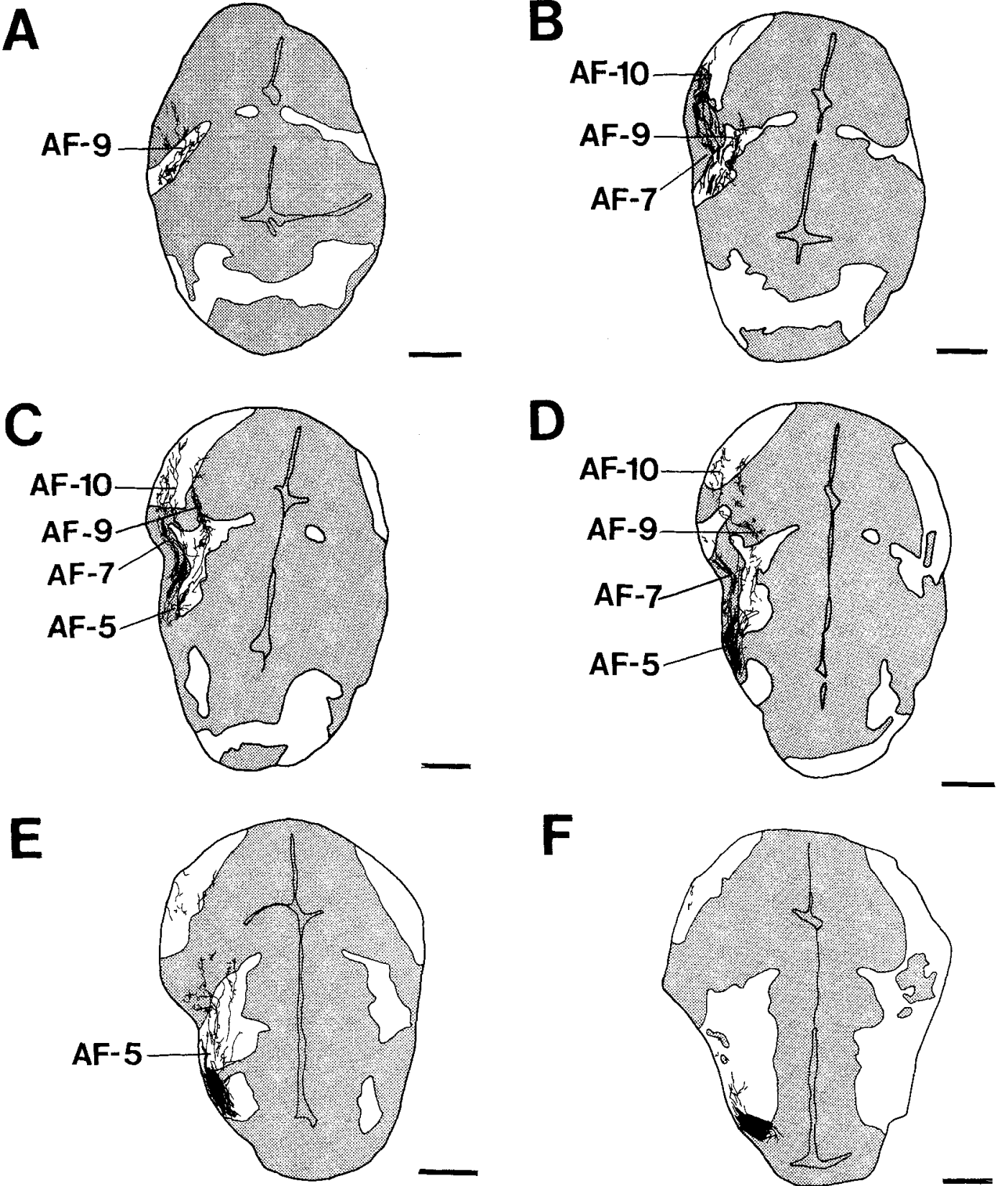

G

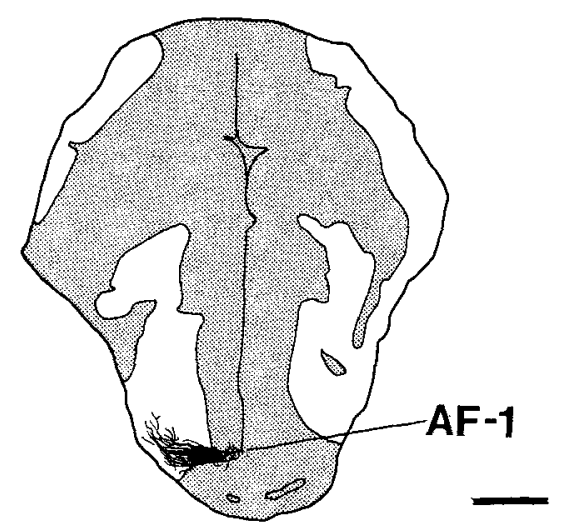

H
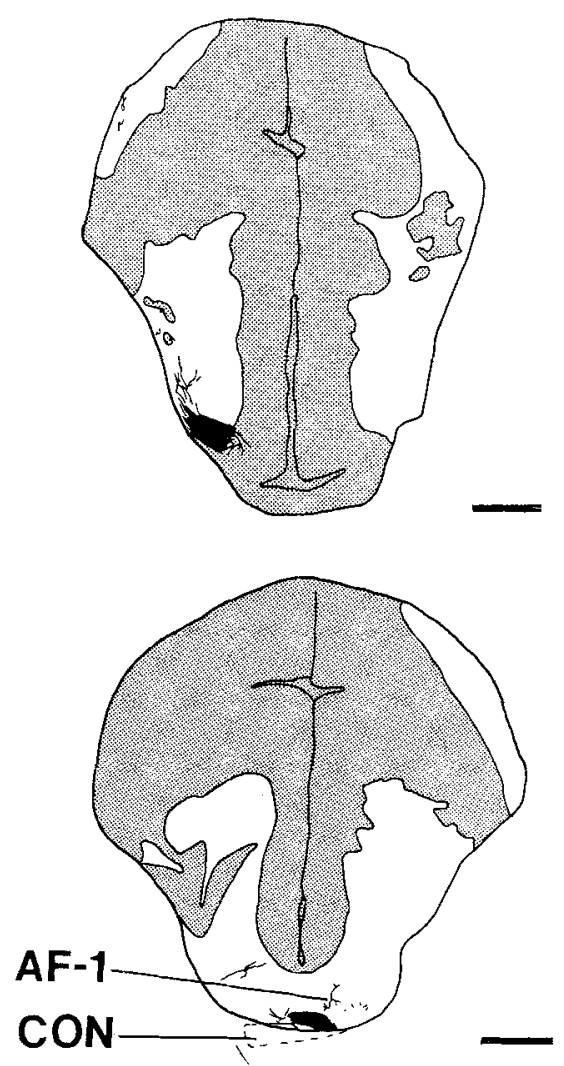

Fig. 6. A-H: Transverse sections through a 60 hour embryo. (Dorsal, up.) Serial $10 \mu \mathrm{m}$ sections taken parallel to the plane indicated by the line in Figure 5. The sections are arranged in serial order from rostral (A) to caudal $(\mathrm{H})$ with one $10 \mu \mathrm{m}$ section missing between both

$\mathrm{E}$ and $\mathrm{F}$, and $\mathrm{G}$ and $\mathrm{H}$. The stippled regions represent the cell nuclei, the empty space represents the neuropil, and the black lines represent the labeled optic axons and their AFs. CON, contralateral optic nerve. Scale bars $=50 \mu \mathrm{m}$. 

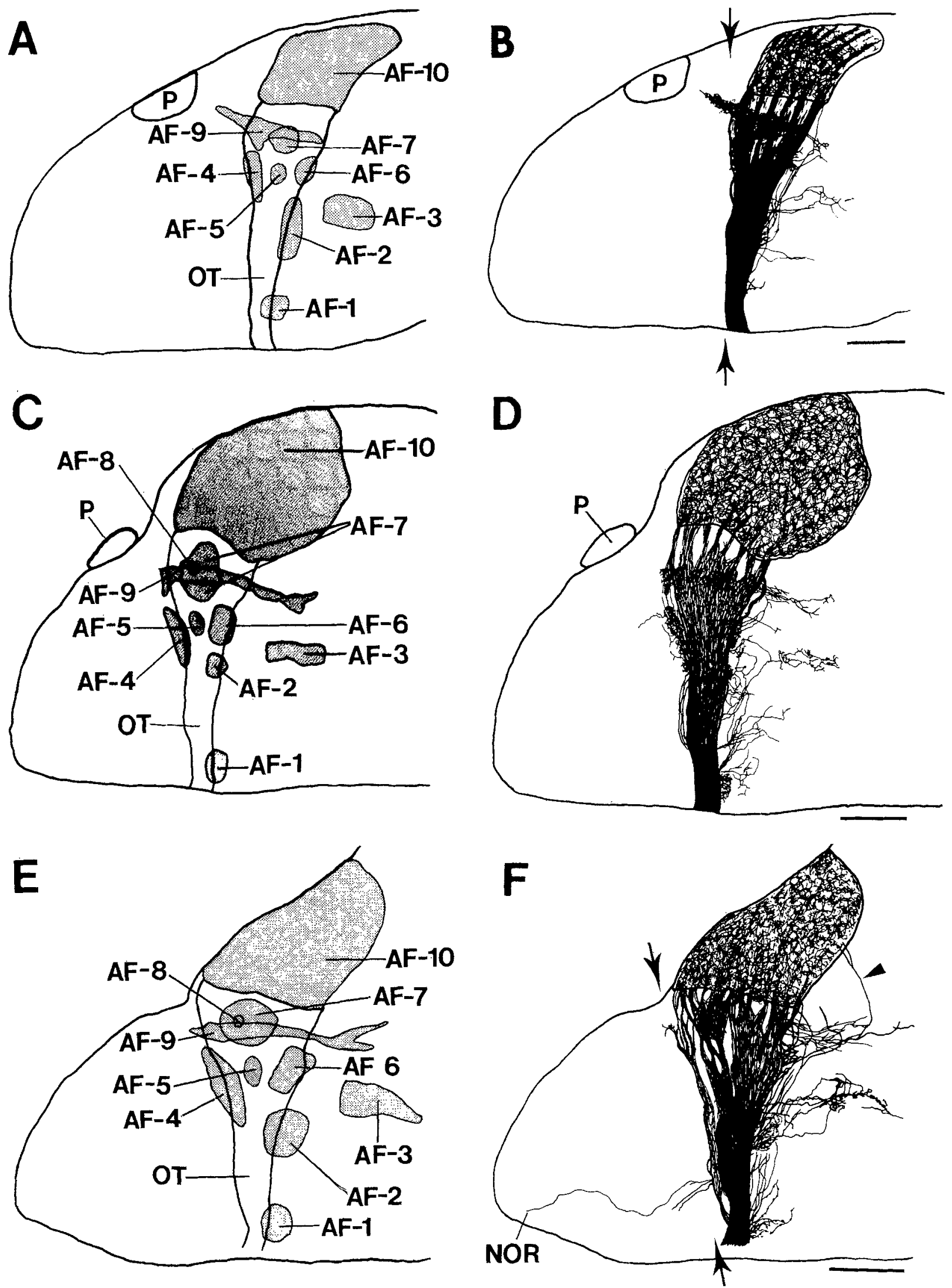

Fig. 7. The AFs at 66 hours, 72 hours, and 6-7 days. (Wholemounts, lateral views: rostral, left; dorsal, up.) A, C, E: Schematic diagrams of the AFs (stippled) visible in wholemounts at 66 hours, 72 hours, and 6-7 days, respectively. B, D, F: Camera lucida drawings of the labeled optic axons and their arborizations at 66 hours, 72 hours, and 6-7 days, respectively. $\mathbf{E}$ and $\mathbf{F}$ are also shown in Figure 2. The approximate location of AF-5 and AF-8 that are not visible in the wholemounts, but

are visible in the transverse sections (see Figs. 8, 9), is also shown. The plane of section for Figures 8 and 9 is shown by arrows in $B$ and $F$, respectively. In F, the arrowhead points to an optic axon from AF-6 that projects $55 \mu \mathrm{m}$ caudally before turning dorsally to innervate AF-10. NOR, nucleus olfactoretinalis; OT, optic tract; P, pineal body. Scale bars $=50 \mu \mathrm{m}$. 


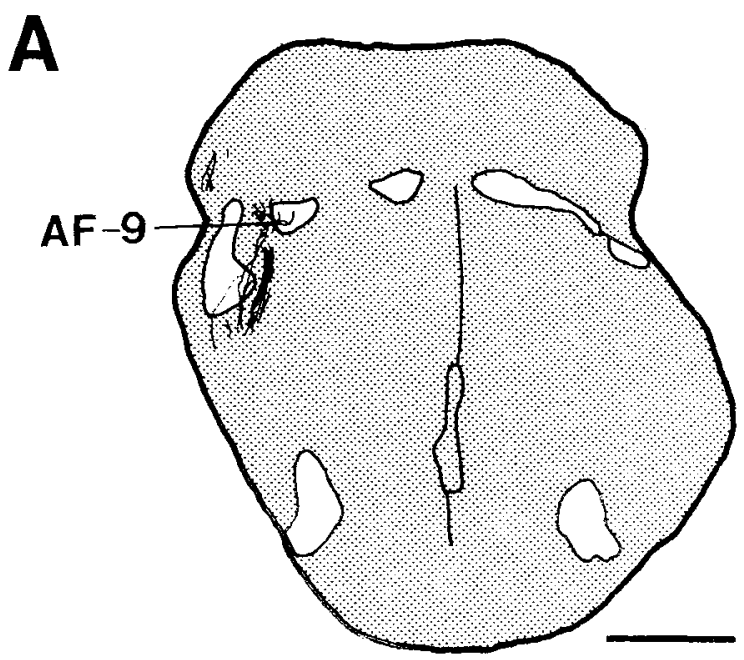

B
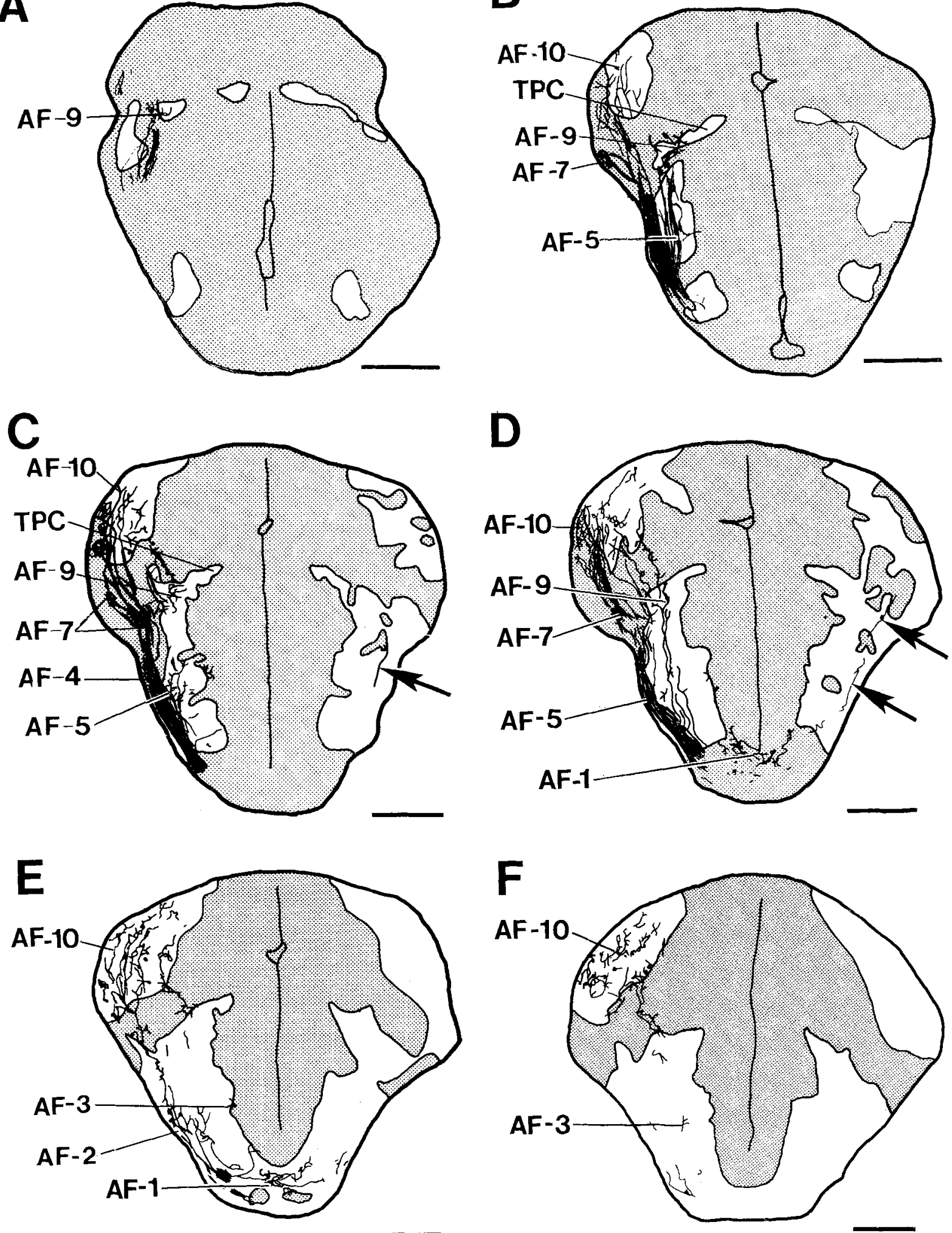

Fig. 8. A-F: Transverse sections through a 66 hour embryo. (Dorsal, up.) Serial $10 \mu \mathrm{m}$ sections taken approximately at the plane indicated by the arrows in Figure 7B are arranged in rostral (A) to caudal $(F)$ order. The stippled regions represent the cell nuclei, the

empty space represents the neuropil, and the black lines represent the labeled optic axons and their AFs. The arrows in $C$ and $D$ point to a single labeled fiber present on the ipsilateral diencephalon that did not arborize. Scale bars $=50 \mu \mathrm{m}$. 
A

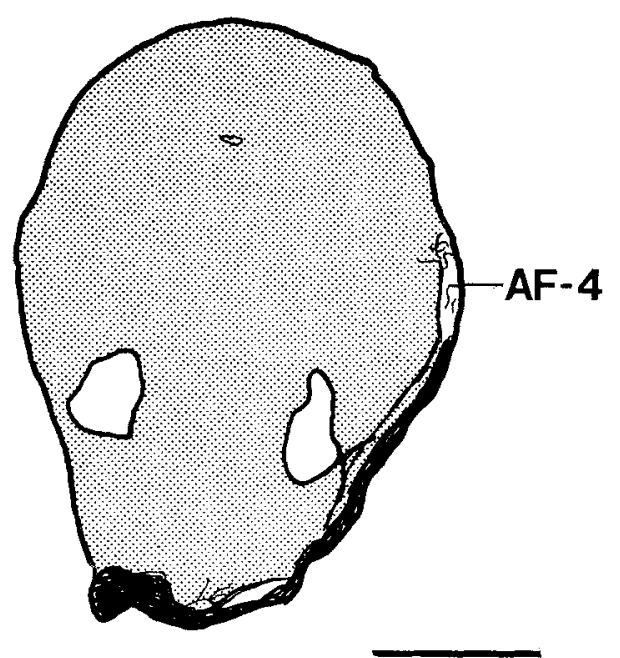

C

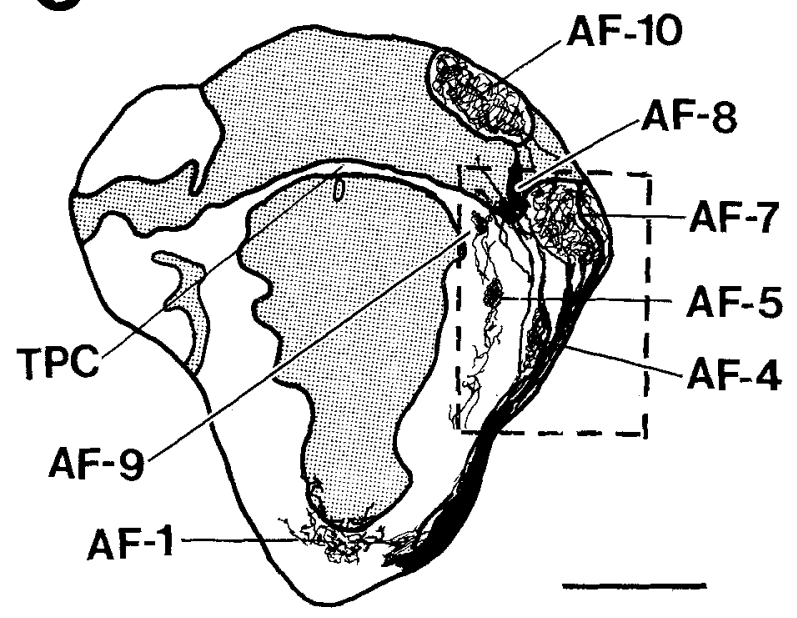

$\mathbf{E}$

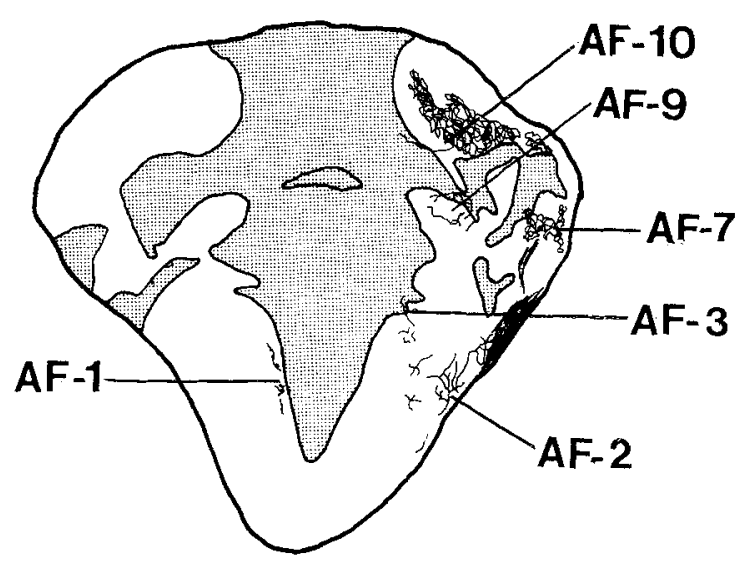

Fig. 9. A-F: Transverse sections through a 6-7 day larva. (Dorsal, up.) Serial $10 \mu \mathrm{m}$ sections taken approximately at the plane indicated by the arrows in Figure $7 \mathrm{~F}$. The sections are arranged serially from rostral (A) to caudal ( $\mathrm{F}$ ); however, one $10 \mu \mathrm{m}$ section between $\mathrm{E}$ and $\mathrm{F}$ is missing. The stippled regions represent the cell nuclei, the empty space
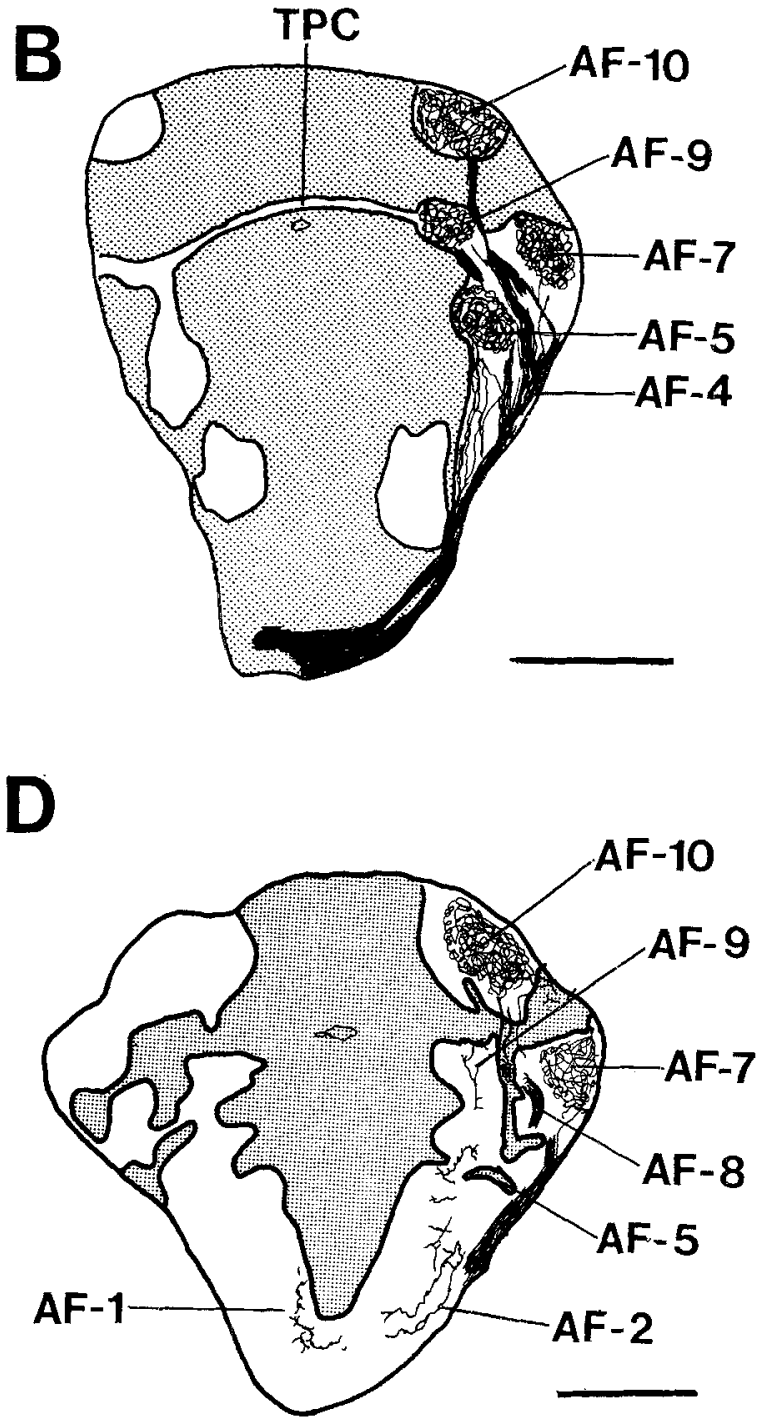

$\mathbf{F}$

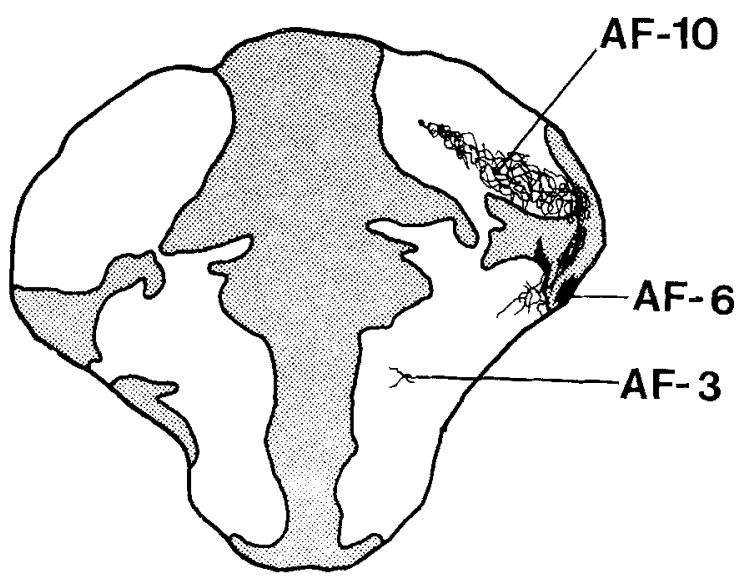

represents the neuropil, and the black lines represent the labeled optic axons and their AFs. A photomicrograph of the boxed region in $\mathrm{C}$ is shown in Figure 11B. The serial sections from the 72 hour embryos were indistinguishable from those at 6-7 days; therefore, only the 6-7 day sections are shown. Scale bars $=50 \mu \mathrm{m}$. 
TABLE 1. Development of the Various AFs ${ }^{1}$

\begin{tabular}{lcccccc}
\hline $\begin{array}{l}\text { Arborization } \\
\text { field }\end{array}$ & $\begin{array}{c}48 \\
\text { hours }\end{array}$ & $\begin{array}{c}52-54 \\
\text { hours }\end{array}$ & $\begin{array}{c}60 \\
\text { hours }\end{array}$ & $\begin{array}{c}66 \\
\text { hours }\end{array}$ & $\begin{array}{c}72 \\
\text { hours }\end{array}$ & $\begin{array}{c}6-7 \\
\text { days }\end{array}$ \\
\hline AF-1 & No & No & Yes & Yes & Yes & Yes \\
AF-2 & No & No & No & Yes & Yes & Yes \\
AF-3 & No & No & No & Yes & Yes & Yes \\
AF-4 & No & No & No & Yes & Yes & Yes \\
AF-5 & No & No & Yes & Yes & Yes & Yes \\
AF-6 & No & No & No & Yes & Yes & Yes \\
AF-7 & No & No & Yes & Yes & Yes & Yes \\
AF-8 & No & No & No & No & Yes & Yes \\
AF-9 & No & Yes & Yes & Yes & Yes & Yes \\
AF-10 & Yes & Yes & Yes & Yes & Yes & Yes \\
\hline
\end{tabular}

${ }^{1}$ The AFs present in wholemounts or sections of various ages.

been observed (Distel and Holländer, 1980; Tolbert and Panneton, 1983; Pittman and Tolbert, 1988). These observations suggest that projections within the CNS initially project exuberantly to target and non-target areas and then those in the non-target areas are removed. In the zebrafish this is clearly not the case; from the earliest time points the retinal axons only projected to areas that were going to remain innervated after hatching and the establishment of a functional visual system, suggesting that the initial axon targeting is quite accurate, with no transient projections. Note that our results do not address the accuracy of the optic projections within the target regions.

\section{Do the arbors make functional connections?}

Optic axons in the AFs are beaded, resembling the terminal swellings seen in adult synaptic fields. It will be necessary to examine the AFs with electron microscopy to determine if they contain synapses.

Behavioral observations indicate that some optic synapses are in place by 6-7 days, since larvae of this age capture prey, apparently on the basis of visual cues (Westerfield, 1989). This implies that the retinotectal projection must be functional, since visual prey capture is mediated by that pathway (Springer et al., 1977), but the functionality of the other AFs is unclear. Even at 6-7 days, all the AFs are in the superficial neuropil, with most somata at a deeper level. This arrangement is maintained in the adult tectum (AF-10), but not in AFs 1-9, in which the optic terminals are associated with clusters of somata. This indicates that the morphology and perhaps even the identity of the post-synaptic cells may be different in the adult and the larva. There are several possible scenarios to account for this difference. First, the optic axons may form synapses with superficial processes from deep cells that later migrate into the AF to form the clusters of somata seen in the adult. Second, the early synapses may be transient on cells that are not contacted in the adult. Later, when cells migrate into the AF, the transient synapses are withdrawn and new ones form on the newly arrived cells, similar to the development of the mammalian cerebral cortex (Shatz and Luskin, 1986; Ghosh et al., 1990). Third, the optic axons may arborize in the appropriate region and wait for their post-synaptic cells to migrate in before they establish any synapses.

\section{Comparison of our AFs with those in adult cypriniformes}

At the stages that we have examined, the neuronal somata that will constitute the various brain nuclei have not yet migrated into the superficial neuropil. Therefore, it was not possible to identify the retinorecipient zones by cytoarchitectonic appearance, so they were recognized by labeled arbors, designated AFs, and numbered. We identified ten retinal AFs in both wholemounts and sections. All but one were exclusively contralateral, the exception being the bilateral AF-1 in the ventral hypothalamus.

The retinofugal projections in adult teleosts include 7-14 different contralateral targets (reviewed by Braford and Northcutt, 1983; Northcutt and Wullimann, 1987). This variation is due, at least in part, to different interpretations of the boundaries of various cell groups and to cross-species variation. The identification of the retinorecipient nuclei is further complicated by the lack of a consensus for the names. We have chosen to follow Northcutt and Wullimann (1987) who have provided a nomenclature that is consistent across the different teleost species, and is cross referenced to many of the names used by other investigators for the same nuclei. The retinorecipient nuclei can be subdivided into five main groups. In the ventrodorsal direction (equivalent to rostrocaudal in the embryo [Ross et al., 1992]), they are the preoptic group containing the nSC and the $\mathrm{nPPp}$; the thalamic group- $n V L, n A$, and nI; the pretectal group-nPSp, the $\mathrm{nPC}$, the nAOD, and the nAOV; the periventricular group-nPPd and the nPPv; and the midbrain-TO

We used the position of the retinorecipient nuclei in adult cypriniformes relative to the optic tract and to each other to identify the AFs in the 6-7 day larvae. Identification of the AFs by matching their relative positions to those present in the adult may mis-identify some of them if drastic morphogenetic movements occur after 7 days, but we believe that this is unlikely because the retinorecipient nuclei in a developing salmonid maintained the same relative positions to each other for at least the first 2 months after hatching (Pinganaud, 1980, 1987).

Four AFs were paired with adult structures because they unambiguously manifested adult attributes. AF-10 was identified as the optic tectum (TO) because it was located in the dorsal midbrain, and is the primary target of the retina in cypriniformes. We have identified AF-1 as the presumptive nSC and the presumptive $\mathrm{nPPp}$ because, similar to the nSC, AF-1 was located adjacent and dorsocaudal to the optic chiasm and was bilaterally innervated, the ipsilateral optic axons having redecussated dorsal to the optic chiasm. The caudal extension of AF-1 observed in the 6-7 day larvae is assumed to be a projection to the presumptive $n P P p$ which is located caudal to the nSC in some adult cypriniformes (Springer and Gaffney, 1981). AF-3 was identified as the presumptive nAOV which is innervated by a group of optic axons that project caudally and medially from the caudal portion of the main optic tract into the region of the presumptive posterior tuberculum. AF-9 was identified as the presumptive nPPd because its position relative to the posterior commissure was similar to that of the nPPd, and because some of the fibers that innervate both the nPPd and AF-9 continue dorsally and innervate the deep layers of the optic tectum (AF-10). In some adult cypriniformes (Braford and Northcutt, 1983) optic axons also project to the $n P P v$ which is located caudal to the nPPd at the same dorsoventral level. We have not seen a separate AF in this region, and suggest that AF-9 represents a projection to both parts, dorsal and ventral, of the same nucleus.

The identifications of the other AFs were more difficult, and the ambiguity of one pairing (e.g., $A F-2 / n V L$ vs. AF-2/nAOD) produced multiple possibilities for the others. Table 3 illustrates six possible assignments. All columns 

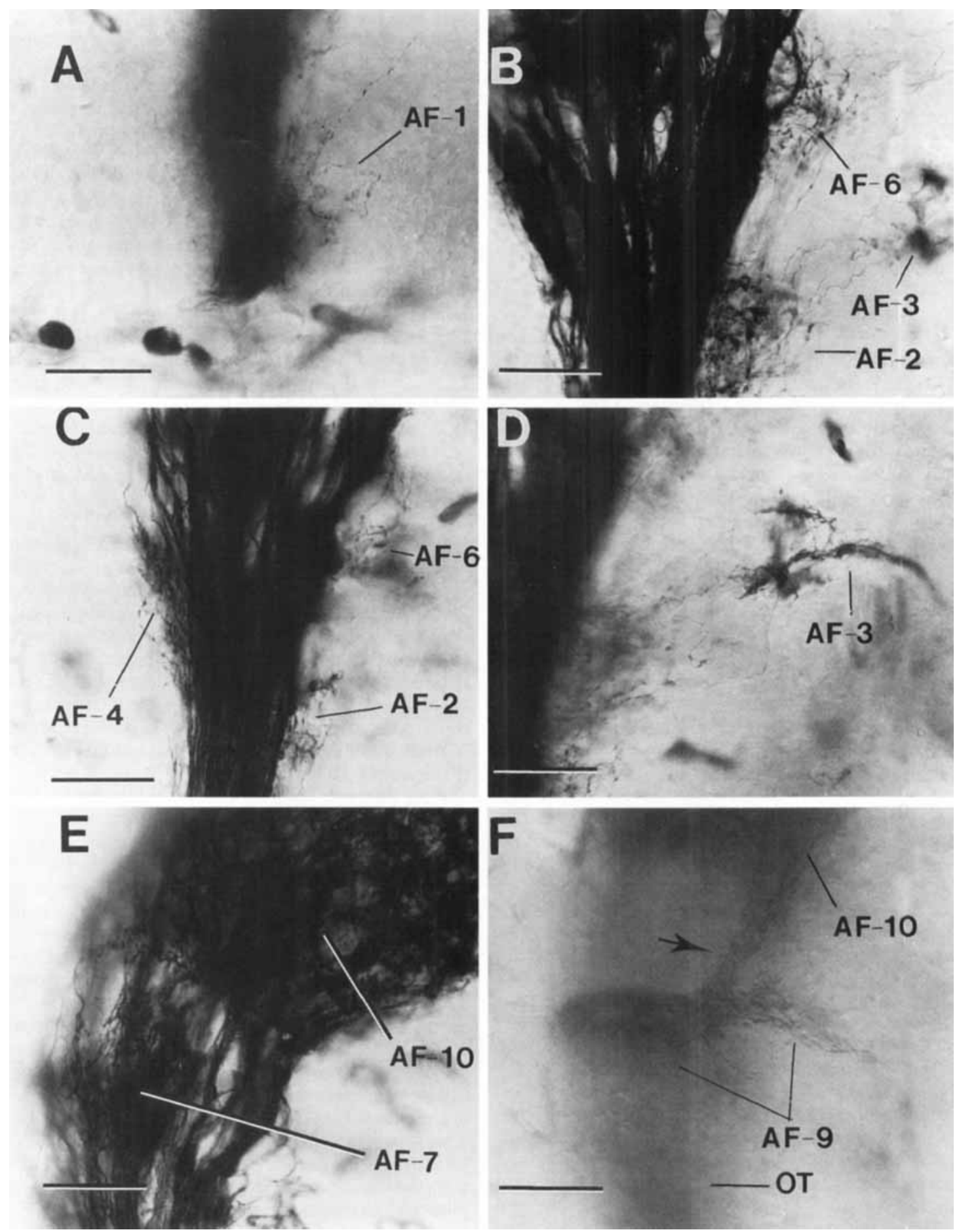

Fig. 10. Individual AFs. (Lateral views: rostral, left; dorsal, up.) Photomicrographs of the individual $A F$ s from wholemounts of 72 hour $(\mathbf{A}, \mathbf{C}, \mathbf{E})$ embryos and 6-7 day larvae (B,D,F). In B, AF-3 is out of focus, but it can be seen in $\mathrm{D}$. A higher magnification view of AF-2 from a

include the relatively certain pairings noted in the preceding paragraph (AF-1/nSC + nPPp, AF-3/nAOV, AF-9/ $n P P d+n P P v, A F-10 / T O$ ) and various possibilities for the other six. Column A gives the most probable assignments. The remainder of this section contains a detailed discussion different embryo is shown in Figure 1. In F the optic tract (OT) and $\mathrm{AF}-10$ are out of focus. Also in $\mathrm{F}$, some of the labeled optic axons (arrow) project dorsally from AF-9 to AF-10. Scale bars $=20 \mu \mathrm{m}$.

of how the assignments in Table 3 were made, a subject of marginal interest to those not intimately involved with teleost neuroanatomy. Such readers might choose to go directly to the next section, "Patterns of ipsilateral innervation." 


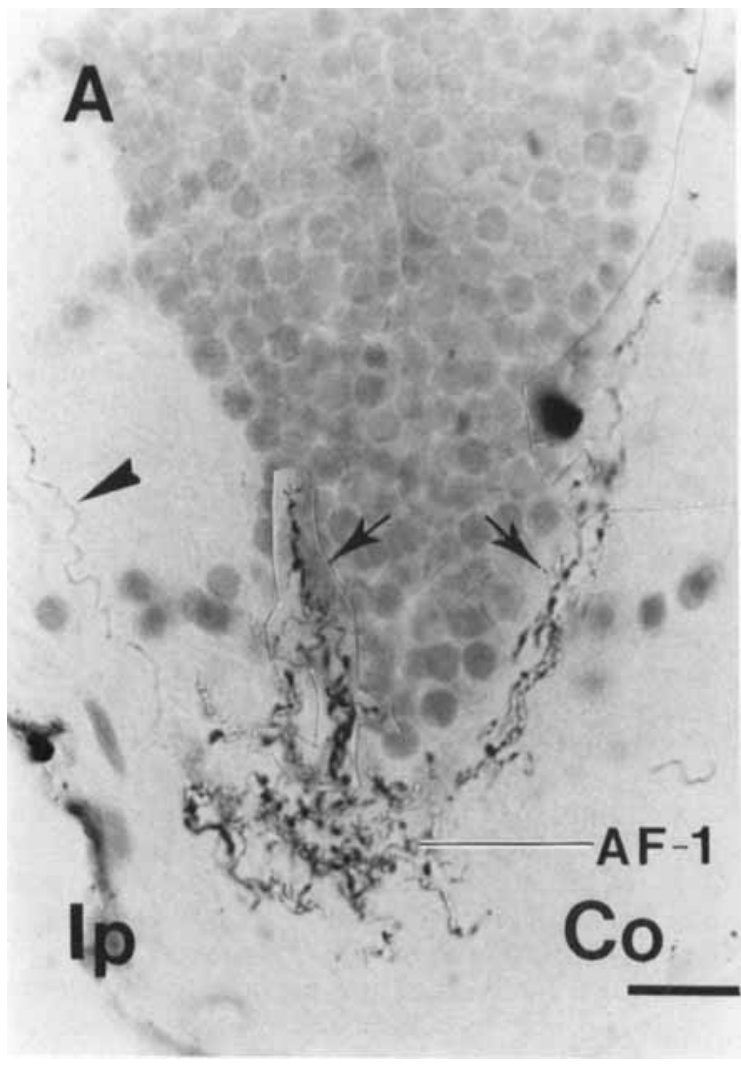

Fig. 11. Photomicrographs of transverse sections through a 6-7 day larva. (Dorsal, up.) A: High magnification view of AF-1 with axons (arrows) that extend dorsocaudally along the medial edge of the lateral neuropil, both contralaterally (Co) and ipsilaterally (Ip). A single axon (arrowhead) projects through AF-1 onto the ipsilateral diencephalon,

TABLE 2. The Individual AFs and Their Potential Adult Identities ${ }^{1}$

\begin{tabular}{ll}
\hline Arborization field & Possible adult structures \\
\hline $\mathrm{AF}-1$ & nSC and $\mathrm{nPPp}$ \\
$\mathrm{AF}-2$ & nAOD or $\mathrm{nVL}$ \\
$\mathrm{AF}-3$ & nAOV \\
$\mathrm{AF}-4$ & nPSp or $\mathrm{nVL}$ or $\mathrm{nI}$ or $\mathrm{nAOD}$ \\
$\mathrm{AF}-5$ & nVL or $\mathrm{nI}$ or $\mathrm{nA}$ \\
$\mathrm{AF}-6$ & nAOD or $\mathrm{nI}$ or $\mathrm{nA}$ \\
$\mathrm{AF}-7$ & $\mathrm{nPC}$ or $\mathrm{nPSp}$ \\
$\mathrm{AF}-8$ & $\mathrm{nPC}$ or $\mathrm{nA}$ \\
$\mathrm{AF}-9$ & nPPd and $\mathrm{nPPv}$ \\
$\mathrm{AF}-10$ & $\mathrm{TO}$ \\
\hline
\end{tabular}

The first name given in the right column is the most likely, and appears in column A of Table 3. The next names are less likely, and are given in one or more of the other columns in Table 3. See text for an explanation of these assignments.

AF-2 may be either the presumptive nVL or the presumptive nAOD. nVL is more likely, as it is the most ventral nucleus of the thalamic group, and the first retinorecipient nucleus dorsal to nSC (AF-1). Alternatively, AF-2 may be the presumptive nAOD, because both occupy a superficial location in the caudal portion of the main optic tract, but this assignment is unlikely for three reasons. First, nAOD is slightly dorsal to $\mathrm{nAOV}$ in adults, but AF-2 is ventral to AF-3 which we believe to be the presumptive nAOV. Second, nAOD is located in the ventral optic tract closer to the optic tectum than to the optic chiasm, but AF-2 is closer to the optic chiasm. Third, AF-6 is a better candidate for $\mathrm{nAOD}$, as both are located superficially in the caudal portion of the main optic tract at a level dorsal to AF-3

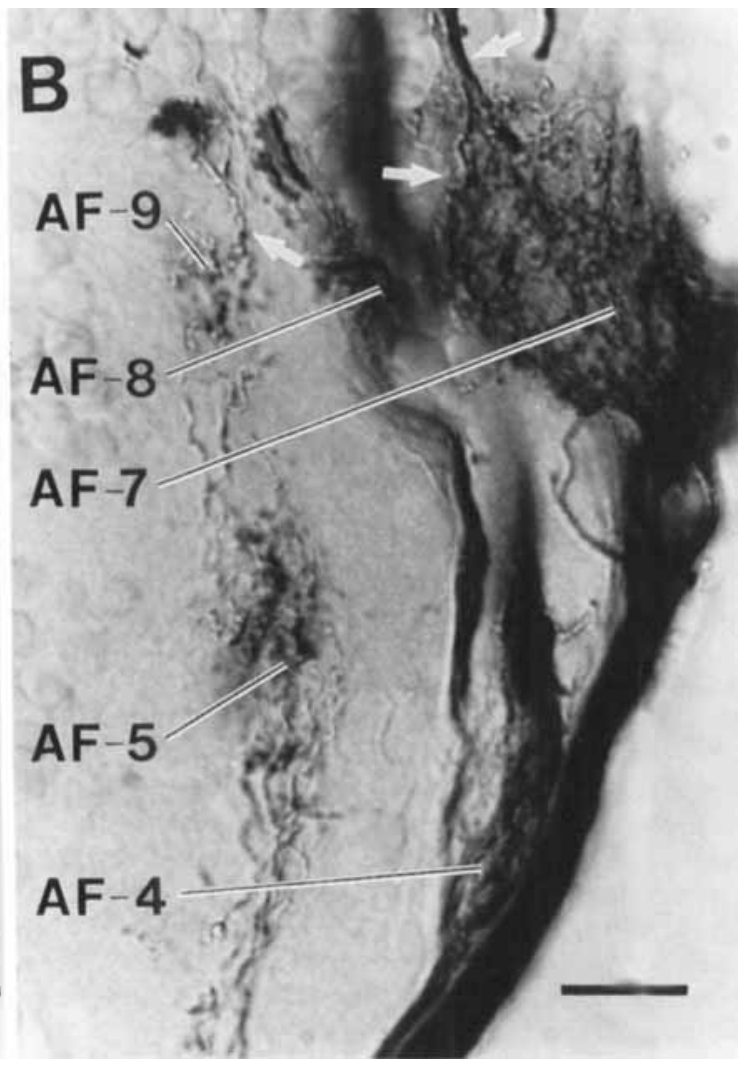

but it does not arborize there. B: High magnification view of the boxed region from Figure $9 \mathrm{C}$. Both $\mathrm{AF}-5$ and $\mathrm{AF}-8$ which are not visible in the wholemounts are present. Also, optic axons that arborize in AF-7 coalesce on the dorsal edge of $A F-7$ and $A F-9$ forming tight fascicles (arrows) that project dorsally to AF-10. Scale bars $=10 \mu \mathrm{m}$.

(nAOV). Therefore, the most likely pairings are $A F-2 / n V L$ and AF-6/nAOD. They are shown in columns $A$ and $B$ of Table 3 .

The thalamic group also contains $\mathrm{nA}$ and $\mathrm{nI}$. $\mathrm{nI}$ is located dorsomedial to $\mathrm{nVL}$ and is the most densely innervated thalamic nucleus in most adult teleosts (G. Striedter, personal communication). If we assume the AF-2/nVL pairing is correct, then presumptive $\mathrm{nI}$ could be either AF-4 or AF-5. Both are dorsal to and more heavily innervated than AF-2, but AF-5 is more likely to be the presumptive $\mathrm{nI}$ because it is also medial to AF-2, and AF-4 is not. AF-4 is most likely the presumptive nPSp because both are the most rostral and both are located superficially near and within the main optic tract at the dorsoventral level of the AF-2/nVL. The remaining member of the thalamic group, $\mathrm{nA}$, is most likely AF-8. The pairings AF-5/nI, AF-4/nPSp, and AF- $8 / \mathrm{nA}$ are entered in column A of Table 3 .

$\mathrm{AF}-7$ is pretectal, and it could be either the presumptive $\mathrm{nPC}$, or the presumptive $\mathrm{nPSp} . \mathrm{AF}-7 / \mathrm{nPC}$ is the more likely alternative because $\mathrm{nPC}$ is located at the same dorsoventral level as nPPd, and at the same mediolateral level as nPSp; AF-7 has similar relationships to AF-9 and AF-4, which we have identified as the presumptive nPPd and nPSp, respectively. This pairing (AF-7/nPC) completes column $A$ of Table 3.

If the arrangement in column A is not correct, what are the most likely alternatives? 
TABLE 3. A Summary of the Potential Identification Schemes for the AFs ${ }^{1}$

\begin{tabular}{|c|c|c|c|c|c|c|}
\hline AFs & A & B & $\mathrm{C}$ & $\mathrm{D}$ & $\mathrm{E}$ & $\mathrm{F}$ \\
\hline AF-1 & $\mathrm{nSC} / \mathrm{nPPp}$ & $\mathrm{nSC} / \mathrm{nPPp}$ & $\mathrm{nSC} / \mathrm{nPPp}$ & $\mathrm{nSC} / \mathrm{nPPp}$ & $\mathrm{nSC} / \mathrm{nPPp}$ & $\mathrm{nSC} / \mathrm{nPPp}$ \\
\hline $\mathrm{AF}-2$ & $\mathrm{nVL}$ & nVL & nVL & nAOD & nAOD & nAOD \\
\hline AF-3 & nAOV & nAOV & nAOV & $\mathrm{nAOV}$ & nAOV & nAOV \\
\hline $\mathrm{AF}-4$ & nPSp & $\mathrm{nI}$ & $\mathrm{nAOD}$ & nVL & $\mathrm{nI}$ & $\mathrm{nPSp}$ \\
\hline$A F-5$ & nI & $\mathrm{nA}$ & $\mathrm{nl}$ & $\mathrm{nI}$ & nVL & $\mathrm{nVL}$ \\
\hline $\mathrm{AF}-6$ & $\mathrm{nAOD}$ & nAOD & $\mathrm{nA}$ & $\mathrm{nA}$ & $\mathrm{nA}$ & nI \\
\hline $\mathrm{AF}-7$ & $\mathrm{nPC}$ & $\mathbf{n P S p}$ & $\mathrm{nPSp}$ & nPSp & nPSp & $\mathrm{nPC}$ \\
\hline $\mathrm{AF}-8$ & $\mathrm{nA}$ & $\mathrm{nPC}$ & $\mathrm{nPC}$ & nPC & $\mathrm{nPC}$ & $\mathrm{nA}$ \\
\hline AF-9 & $n P P d / n P P v$ & $\mathrm{nPPd} / \mathrm{nPPy}$ & $\mathrm{nPPd} / \mathrm{nPPv}$ & $\mathrm{nPPd} / \mathrm{nPPv}$ & $\mathrm{nPPd} / \mathrm{nPPv}$ & $\mathrm{nPPd} / \mathrm{nPPv}$ \\
\hline$A F-10$ & To & TO & TO & TO & To & TO \\
\hline
\end{tabular}

${ }^{1}$ The different AFs are listed in the first column, and their possible adult identities are in the other columns. The identification scheme listed in column A is most likely to be correct. See text for details.

The greatest ambiguity is in the identification of AF-7, which in turn allows multiple possibilities for AF-4, AF-5, $\mathrm{AF}-6$, and $\mathrm{AF}-8$. If $\mathrm{AF}-7$ is identified as $\mathrm{nPSp}$, then either $\mathrm{AF}-4$ or $\mathrm{AF}-5$ is $\mathrm{nI}$. If $\mathrm{AF}-4$ is $\mathrm{nI}$, then $\mathrm{AF}-5$ is $\mathrm{nA}$, and AF-8 is nPC (Table 3 , column $B$ ). As previously mentioned, this is less likely than the arrangement in column $\mathrm{A}$ because it puts $\mathrm{nI}(\mathrm{AF}-4)$ lateral to $\mathrm{nVL}(\mathrm{AF}-2)$. If AF-5 is taken as nI, then either AF-4 or AF-6 must be nA. In adults $n I$ is more heavily innervated than, and rostral to, $\mathrm{nA}$, so it is unlikely that AF-4 is the presumptive $n A$ because AF-4 is more heavily innervated than, and rostral to, AF-5. Therefore AF-6 is chosen as nA, which forces AF-4 to be nAOD (Table 3 , column $\mathrm{C}$ ). This is an unlikely arrangement because AF-4 is located within the rostral portion of the main optic tract and the adult $\mathrm{nAOD}$ is located in the caudal portion.

The other principal uncertainty is the identity of AF-2. If it is identified as nAOD and not nVL then either AF-4 or AF-5 must be the presumptive $n V L$ because they are the most ventral of the remaining AFs. If AF-4 is nVL, then AF-5 is nI, AF-6 is nA, AF-7 is nPSp, and AF-8 is nPC (Table 3 , column D). This is problematic because AF-4 extends dorsal to AF-5, but in adults $n V L$ is ventral to $n I$. If $\mathrm{AF}-5$ is taken as $\mathrm{nVL}$ then the arrangements of columns $\mathrm{E}$ and $\mathrm{F}$ (Table 3 ) follow. They are problematic because either AF-4 (column E) or AF-6 (column F) must be nI, but both are lateral to AF-5, and in the adult thalamus $\mathrm{nI}$ is medial to nVL.

\section{Patterns of ipsilateral innervation}

Diencephalic targets are innervated ipsilaterally in a variety of teleosts (Repérant et al., 1976; Voneida and Sligar, 1976; Springer and Landreth, 1977; Peyrichoux et al., 1977; Ebbesson and Ito, 1980; Springer and Gaffney, 1981; Prasada Rao and Sharma, 1982; Braford and Northcutt, 1983; Springer and Mednick, 1985; Collin, 1989). The optic axons that innervate the ipsilateral diencephalon arrive there by three different pathways: 1) through the ipsilateral optic tract without decussating in the optic chiasm (Voneida and Sligar, 1976), 2) by two decussations, the first in the chiasm, and the second in the region dorsal to the chiasm (Braford and Northcutt, 1983), and 3) by two decussations, the first in the chiasm, and the second through the posterior commissure (Springer and Landreth, 1977; Braford and Northcutt, 1983). In the developing zebrafish the only ipsilateral projection resulted from the third of these. We have no suggestions for why the ipsilateral terminations should result from such different trajectories in fish, or why two of the three trajectories in fish should be so different from what has been described in mammals.

\section{AF formation}

Early in development all of the optic axons in the zebrafish projected toward the optic tectum in a relatively straight line. The initial optic axons reach the rostral pole of the tecturn at about 44 hours, cover the rostral half by 52-54 hours, and completely innervate the tectum by 72 hours, confirming Stuermer (1988).

At 48 hours, 4 hours after the initial innervation of the optic tectum, some optic axons left the optic tract and projected along either the TPC toward the presumptive nPPd or caudally along the TPOC in the mid-diencephalon, possibly toward the presumptive nAOV. The optic axons near the TPC reached the presumptive nPPd and established an AF by 52 hours, while those in the middiencephalon either continued to project caudally toward the nAOV, or they turned dorsally toward the optic tectum again. Between 52 hours and 66 hours ( 6 hours prior to hatching) the rest of the AFs were established (Table 1). This general schedule-innervate the tectum first and fill in the others later-has been noted in many vertebrates: trout (Pinganaud, 1980, 1987), newt (Rettig et al., 1981; Rettig, 1988), hamster (Frost et al., 1979; Bhide and Frost, 1991), frog (Currie and Cowan, 1974; Kennard, 1981), and chick (O'Leary et al., 1983). Similarly, the developing cortex projects to the most distal targets first, and the more proximal ones later on (Distal and Holländer, 1980).

It is interesting to note that the first non-tectal nuclei to receive retinal innervation in both the newt and the zebrafish are located in similar locations (Rettig et al., 1981; Rettig, 1988). In the newt the first one is the basal optic neuropil located caudal to the main optic tract in the midbrain, a similar position to the presumptive nAOV in the zebrafish. The second is the posterior thalamic nucleus located just ventral to the tectum in the main optic tract roughly similar to the $\mathrm{nPPd}$ (Rettig et al., 1981; Rettig, 1988). It remains to be determined if there is any functional significance to the early innervation to these nuclei. The order of projection to the retinorecipient targets is not based simply on their proximity to either the optic tectum or the retina because the $n P P d$ is near the optic tectum and the $\mathrm{nSC}$ is near the retina and they are two of the first non-tectal targets to be innervated.

One final comment concerns "interstitial budding" of collateral axons, which has been described by others (Sachs et al., 1986; Stanfield et al., 1987; O'Leary and Terashima, 1988; Bhide and Frost, 1991; Jhaveri et al., 1991). As the tectum was both the most distant site and the first one to be innervated, we might expect to see some of the other AFs innervated by interstitial budding of retinotectal axons. 
Two of the AFs (3 and 9) were sufficiently lateral to the optic tract that interstitial buds could have been discerned. Both of them were innervated by bundles of axons that diverged from the main tract (Figs. 3, 4), and not from interstitial buds of axons in the main tract. We cannot exclude interstitial budding in the other AFs, as they were so close to the main tract that buds could not be detected by our method. Similarly, we cannot exclude interstitial budding later in development.

\section{CONCLUSIONS}

We have shown that the optic projection to the tectum is the first to appear, and the others begin to develop shortly thereafter. By 72 hours, approximately the time of hatching, all of the anlagen of the adult retinorecipient targets have appeared, and the numbers of axons that project to and through them increased over the next several days. The initial AFs were formed by principal axons, not collaterals, but by 6-7 days optic axons may terminate in more than one AF. In addition, we have shown that the optic axons do not form any transient projections to areas not innervated at 6-7 days, thus suggesting that the initial targeting of the retinal axons is very accurate.

\section{ACKNOWLEDGMENTS}

We thank Celesté Malinoski for her excellent technical assistance, and Drs. Riva Marcus, Georg Striedter, Charlotte Mistretta, and David Cameron for their helpful comments and discussion. This work was supported by NIH grants RO1-EY-00168 and T32-EY-007022.

\section{LITERATURE CITED}

Adams, C.E., G.A. Mihailoff, and D.J. Woodward (1983) A transient component of the developing corticospinal tract arises in visual cortex. Neurosei. Lett. 36:243-248.

Beazley, L.D. (1984) Formation of specific synaptic connections in the visual system of lower vertebrates. In D.G. Jones (ed): Current Topics in Research on Synapses, Vol. 1. New York: Alan R. Liss, Inc, pp 53-117.

Bhide, P.G., and D.O. Frost (1991) Stages of growth of hamster retinofugal axons: implications for developing axonal pathways with multiple targets. J. Neurosci. 11:485-504.

Braford, M.R., Jr., and R.G. Northcutt (1983) Organization of the diencephalon and pretectum of the ray-finned fishes. In R.E. Davis and R.G. Northcutt (eds): Fish Neurobiology, Vol. 2. Ann Arbor: University of Michigan Press, pp. 117-163.

Bunt, S.M., and R.D. Lund (1981) Developmental of a transient retinoretinal pathway in hooded and albino rats. Brain Res. 211:399-404.

Burrill, J.D., S.W. Wilson, and S.S. Easter, Jr. (1989) Early development of the zebrafish visual pathway. Invest. Ophthalmol. Vis. Sci. 30:226.

Campbell, G., and D.O. Frost (1988) Synaptic organization of anomalous retinal projections to the somatosensory and auditory thalamus: targetcontrolled morphogenesis of axon terminals and synaptic glomeruli. $\mathrm{J}$. Comp. Neurol. 272:383-408.

Chitnis, A.B., and J.Y. Kuwada (1990) Axogenesis in the brain of zebrafish embryos. J. Neurosci. 10:1892-1905.

Collin, S.P. (1989) Anterograde labelling from the optic nerve reveals multiple central targets in the teleost, Lethrinus chrysostomus (perciformes). Cell Tissue Res. 256:327-335.

Cooper, A.M., and A. Cowey (1990a) Development and retraction of a crossed retinal projection to the inferior colliculus in neonatal pigmented rats. Neuroscience 35:335-344.

Cooper, A.M. and A. Cowey (1990b) Retinal topography of the neonatal crossed aberrant exuberant projection to the inferior colliculus in the pigmented rat. Neuroscience 35:345-354.

Currie, J., and W.M. Cowan (1974) Evidence for the late development of the uncrossed retinothalamic projections in the frog, Rana pipiens. Brain Res. 71:133-139.
Dehay, C., J. Bullier, and H. Kennedy (1984) Transient projections from the fronto-parietal and temporal cortex to areas 17,18 , and 19 in the kitten. Exp. Brain Res. 57:208-212.

Distel, H., and H. Holländer (1980) Autoradiographic tracing of developing subcortical projections of the occipital region in fetal rabbits. J. Comp. Neurol. 192:505-518.

Easter, S.S., Jr., D. Purves, P. Rakic, and N.C. Spitzer (1985) The changing view of neural specificity. Science 230:507-511.

Ebbesson, S.O.E., and H. Ito (1980) Bilateral retinal projections in the black piranha (Serrasalmus niger). Cell Tissue Res. 213:483--495.

Frost, D.O. (1981) Orderly anomalous retinal projections to the medial geniculate, ventrobasal, and lateral posterior nuclei of the hamster. J. Comp. Neurol. 203:227-256.

Frost, D.O. (1984) Axonal growth and target selection during development: retinal projections to the ventrobasal complex and other "nonvisual" structures in neonatal Syrian hamsters. J. Comp. Neurol. 230:576-592.

Frost, D.O., and C. Métin (1985) Induction of functional retinal projections to the somatosensory system. Nature $317: 162-164$.

Frost, D.O., K.-F. So, and G.E. Schneider (1979) Postnatal development of retinal projections in Syrian hamsters: a study using autoradiographic and anterograde degeneration techniques. Neuroscience 4:1649-1677.

Ghosh, A., A. Antonini, S.K. McConnell, and C.J. Shatz (1990) Requirement for subplate neurons in the formation of thalamocortical connections. Nature 347:179-181.

Godement, P., J. Vanselow, S. Thanos, and F. Bonhoeffer (1987) A study in developing visual systems with a new method of staining neurons and their processes in fixed tissue. Development 101:697-713.

Honig, M.G., and R.I. Hume (1986) Fluorescent carbocyanine dyes allow living neurons of identified origin to be studied in long-term cultures. J. Cell Biol. 103:171-187.

Innocenti, G.M., and S. Clarke (1984) Bilateral transitory projection to visual areas from auditory cortex in kittens. Dev. Brain Res. 14:143-148.

Jhaveri, S., M.A. Edwards, and G.E. Schneider (1991) Initial stages of retinofugal axon development in the hamster: evidence for two distinct modes of growth. Exp. Brain Res. 87:371-382.

Kato, T. (1983) Transient retinal fibers to the inferior colliculus in the newborn albino rat. Neurosei. Lett. 37:7-9.

Kato, T., A. Hirano, T. Katagiri, and H. Sasaki (1985a) Transient uncrossed corticospinal fibres in the newborn rat. Neuropathol. Appl. Neurobiol. 11:171-178.

Kato, T., A. Hirano, K. Honda, T. Katagiri, and H. Saski (1985b) Transient retino-inferior collicular fibres in neonatal rats: their persistence after removal of one eye at birth. Neuropathol. Appl. Neurobiol. 11:265-272.

Kennard, C. (1981) Factors involved in the development of ipsilateral retinothalamic projections in Xenopus laevis. J. Embryol. Exp. Morphol. 65:199-217.

Kljavin, I.J. (1987) Early development of photoreceptors in the ventral retina of the zebrafish embryo. J. Comp. Neurol. 260:461-471.

Land, P.W., and R.D. Lund (1979) Development of the rat's uncrossed retinotectal pathway and its relation to plasticity studies. Science 205:698-700.

Langdon, R.B., and D.O. Frost (1991) Transient retinal axon collaterals to visual and somatosensory thalamus in neonatal hamsters. J. Comp. Neurol. 310:200-214.

Lund, R.D., J.S. Lund (1971) Synaptic adjustment after deafferentation of the superior colliculus of the rat. Science 171:804-807.

McConnell, S.K., A. Ghosh, and C.J. Shatz (1989) Subplate neurons pioneer the first axon pathway from the cerebral cortex. Science 245:978-982.

Müller, M., and H. Holländer (1988) A small population of retinal ganglion cells projecting to the retina of the other eye. An experimental study in the rat and the rabbit. Exp. Brain Res. 71:611-617.

Nawrocki, L.W. (1985) Development of the neural retina in the zebrafish, Brachydanio rerio. Doctoral dissertation, University of Oregon, Eugene.

Northcutt, R.G., and M.F. Wullimann (1987) The visual system in Teleost fishes: morphological patterns and trends. In (J. Atema, Fay, A.N. Popper, and W.N. Tavolga (eds): Sensory Biology of Aquatic Animals. New York: Springer-Verlag, pp. 515-552.

O'Leary, D.D.M., and T. Terashima (1988) Cortical axons branch to multiple subcortical targets by interstitial axon budding: implications for target recognition and "waiting periods". Neuron 1:901-910.

O'Leary, D.D.M., C.R. Gerfen, and W.M. Cowan (1983) The development and restriction of the ipsilateral retinofugal projection in the chick. Dev. Brain Res. 10:93-109. 
Peyrichoux, J., C. Weidner, J. Repérant, and D. Miceli (1977) An experimental study of the visual system of cyprinid fish using the HRP method. Brain Res. 130:531-537.

Pinganaud, G. (1980) Le dv́eloppement du système visuel primaire de Salmo irideus. Arch. Anat. Micrsc. Morphol. Exp. 69:215-231.

Pinganaud, G. (1987) Mise en place de la rétinotopie au cours du développement de l'alevin de truite Salmo gairdneri Rich. J. Hirnforsch. 28:71-89.

Pittman, T., and D.L. Tolbert (1988) Organization of transient projections from the primary somatosensory cortex to the cerebellar nuclei in kittens. Anat. Embryol. (Berl.) 178:441-447.

Prasada Rao, P.D., and S.C. Sharma (1982) Retinofugal pathways in juvenile and adult channel catfish, Ictalurus (Ameiurus) punctatus: an HRP and autoradiographic study. J. Comp. Neurol. 210:37-48.

Repérant, J., M. Lemire, D. Miceli, and J. Peyrichoux (1976) A radioautographic study of the visual system in fresh water teleosts following intraocular injection of tritiated frucose and proline. Brain Res. 118:123131.

Rettig, G. (1988) Development of retinofugal neuropil areas in the brain of the alpine newt, Triturus alpestris II. Topographic organization and formation of projections. Anat. Embryol. (Berl.) 177:257-265.

Rettig, G., B. Fritzsch, and W. Himstedt (1981) Development of retinofugal neuropil areas in the brain of the alpine newt, Triturus alpestris. Anat. Embryol. (Berl.) 162:163-171.

Ross, L.S., T. Parrett, and S.S. Easter, Jr. (1992) Axonogenesis and morphogenesis in the embryonic zebrafish brain. J. Neurosei. 12:467482.

Sachs, G.M., M. Jacobson, and V.S. Caviness, Jr. (1986) Postnatal changes in arborization patterns of murine retinocollicular axons. J. Comp. Neurol. 246:395-408

Santacana, M., M. Heredia, and F. Valverde (1992) Transient pattern of exuberant projections of olfactory axons during development in the rat. Dev. Brain Res. 70:213-222.

Schmidt, J.T. (1982) The formation of retinotectal projections. Trends Neurosci. 5:111-116.

Shatz, C.J. and M.B. Luskin (1986) The relationship between the geniculocortical afferents and their cortical target cells during development of the cat's primary visual cortex. J. Neurosci. 6:3655-3668.

Simon, D.K. and D.D.M. O'Leary (1992) Development of topographic order in the mammalian retinocollicular projection. J. Neurosci. 12:1212 1232.
So, K.-F., G.E. Schneider, and D.O. Frost (1978) Postnatal development of retinal projections to the lateral geniculate body in Syrian hamsters. Brain Res. 142:343-352.

Springer, A.D., and J.S. Gaffney (1981) Retinal projections in the goldfish: a study using colbatous-lysine. J. Comp. Neurol. 203:401-424.

Springer, A.D., and G.L. Landreth (1977) Direct ipsilateral retinal projections in goldfish (Carassius auratus). Brain Res. 124:533-537.

Springer, A.D., and A.S. Mednick (1985) A quantitative study of the relative contribution of different retinal sectors to the innervation of various thalamic and pretectal nuclei in goldfish. J. Comp. Neurol. 242:369-380.

Springer, A.D., S.S. Easter, Jr., and B.W. Agranoff (1977) The role of the optic tectum in various visually mediated behaviors of goldfish. Brain Res. 128:393-404.

Stanfield, B.B., D.D.M. O'Leary, and C. Fricks (1982) Selective collateral elimination in early postnatal development restricts cortical distribution of rat pyramidal tract neurones. Nature 298:371-373.

Stanfield, B.B., B.R. Nahin, and D.D.M. O'Leary (1987) A transient postmam millary component of the rat forinx during development: implications for interspecific differences in mature axonal projections. J. Neurosci. 7:3350-3361.

Stuermer, C.A.O. (1988) Retinotopic organization of the developing retinotectal projection in the zebrafish embryo. J. Neurosci. 8:4513-4530.

Stuermer, C.A.O., B. Rohrer, and H. Münz (1990) Development of the retinotectal projection in zebrafish embryos under TTX-induced neural impulse blockade. J. Neurosci. 10:3615-3626.

Tolbert, T.L., and W.M. Panneton (1983) Transient cerebrocerebellar projections in kittens: postnatal development and topography. J. Comp. Neurol. 221:216-228.

von Bartheld, C.S., and D.L. Meyer (1988) Retinofugal and retinopetal projections in the teleost Channa micropeltes (channiformes). Cell Tissue Res. 251:651-663.

Voneida, T.L., and C.M. Sligar (1976) A comparative neuroanatomic study of retinal projections in two fishes: Astyanax hubbsi (the blind cave fish), and Astyanax mexicanus. J. Comp. Neurol. 165:89-106.

Webster, M.J., L.G. Ungerleider, and J. Bachevalier (1991) Connections of the inferior temporal areas $\mathrm{Te}$ and $\mathrm{Teo}$ with medial temporal-lobe structures in infant and adult monkeys. J. Neurosci. 11:1095-1116.

Westerfield, M. (1989) The Zebrafish Book. Eugene, OR: University of Oregon Press.

Wilson, S.W., L.S. Ross, T. Parrett, S.S. Easter, Jr. (1990) The development of a simple scaffold of axon tracts in the brain of the embryonic zebrafish Brachydanio rerio. Development 108:121-145. 